\title{
Impact-Induced Tensional Failure in Rock
}

\author{
ThOMAS J. AHRENS AND ALLAN M. RUBin 1 \\ Lindhurst Laboratory of Experimental Geophysics, Seismological Laboratory \\ California Institute of Technology, Pasadena
}

\begin{abstract}
Planar impact experiments were employed to induce dynamic tensile failure in Bedford limestone. Rock discs were impacted with aluminum and polymethyl methacralate flyer plates at velocities of 10 to $25 \mathrm{~m} / \mathrm{s}$. This resulted in tensile stresses in the range of $\sim 11$ to $160 \mathrm{MPa}$. Tensile stress durations of 0.5 and $1.3 \mu \mathrm{s}$ induced microcrack growth which in many experiments were insufficient to cause complete spalling of the samples. Ultrasonic $P$ and $S$ wave velocities of recovered targets were compared to the velocities prior to impact. Velocity reduction, and by inference microcrack production, occurred in samples subjected to stresses above $35 \mathrm{MPa}$ in the 1.3- $\mu \mathrm{s}$ PMMA experiments and $60 \mathrm{MPa}$ in the $0.5-\mu$ s aluminum experiments. Apparent fracture toughnesses of 2.4 and $2.5 \mathrm{MPa}$ $\mathrm{m} / 2$ are computed for the 1.3- and 0.5 - $\mu$ s experiments. These are a factor of -2 to 6 greater than quasi-static determinations. Three-dimensional impact experiments were conducted on $20 \mathrm{~cm}$-sized blocks of Bedford limestone and San Marcos gabbro. Compressional wave velocity deficits up to 50-60\% were observed in the vicinity of the crater. These damage levels correspond to O'Connell and Budiansky damage parameters of 0.4 as compared to the unshocked rock. The damage decreases as $\sim r^{-1.5}$ from the crater indicating a dependence on the magnitude and duration of the tensile pulse. Using the observed variation in damage with tensile stress from the one-dimensional experiments, and estimates of the variation of peak dynamic tensile stress and tensile stress duration with distance from an impact on an elastic half-space, the observed dependence of damage with radius in the three-dimensional experiments are theoretically predicted and compare favorably to experimental data
\end{abstract}

\section{INTRODUCTION}

Impact-induced cracling of rock beneath impact craters and in the rocks surrounding contained explosions have long been recognized both on Earth and the Moon. As early as 1968, Short [1968] reported the systematic crack-induced reduction (by as much as $42 \%$ ) in the compressional wave velocity $\left(C_{p}\right)$ in rocks surrounding the underground explosion, Hardhat. Similarly, large scale reductions in compressional wave velocity were reported beneath the -1km-diameter Barringer (Meteor) impact crater in Arizona [Ackeman et al., 1975], as well as the considerably larger ( 35 and $20 \mathrm{~km}$ diameter) Ries crater in Germany [Pohl et al., 1977] and Haughton dome crater in Canada [Hajnal et al., 1988]. More recently, Ackerman et al. [1986] have reported substantial velocity deficits beneath the $1-\mathrm{km}$-diameter explosion crater (Eniwetok) produced by the 10-Mt surface explosion, Oak. Seismic refraction studies on the Moon, and virtually all the rocks returned from the Moon, indicate that shock-induced fractures reduce the observed seismic velocity from intrinsic values. Simmons et al. [1973] pointed out that virtually the entire crust of the Moon, down to the depth of $-25 \mathrm{~km}$, suffers shock-induced crack damage, and the in situ velocity is substantially below the intrinsic values of the rocks present (e.g., gabbros, norites, and pyroxenites). Related to the crack-induced seismic velocity deficits is a series of recognized deficits in the local gravity field beneath large young craters on Earth and the Moon [Dvorak and Phillips, 1977; Jvanov, 1989]. Cracking beneath small-scale laboratory impact craters has been previously described [Hörz, 1969; Manrer and Rinehart, 1960; Moore et al., 1963; Polanskey and Ahrens, 1990]. However, the physical mechanisms which produce the different types of fractures have only partially been discussed

\footnotetext{
Tow at Department of Geological Sciences, Princeton University. Princeton, New Jersey.
}

Copyright 1993 by the American Geophysical Union.

Paper number 92JE02679.

0148-0227/93/92JE-02679\$05.00 previously [e.g., Melosh 1989, chapter 5]. Another related issue which remains unstudied is the effect of large-scale gravity-induced late-stage cratering motions on rock properties. Presumably, rock cracking occurs upon crater rebound that transforms large bowl-shaped transient cavities into flat-floored and multiringed craters [ $O$ 'Keefe and Ahrens, 1989; also Planetary cratering mechanics, submitted to Journal of Gcophysical Research, 1992]. In the present paper we analyze data from two rocks, Bedford (Indiana) limestone and San Marcos, (California) gabbro, damaged in one- and three-dimensional impact experiments. These rocks are studied because they are representative of crustal rock types and impact and strength tests for specimens from these localities have been performed previously .

Our goal was to understand the relation of dynamic production of cracks beneath craters, to the concurrent reduction in elastic moduli and quasi-static strength. This relation may be important to inferring the impact or explosion parameters which produce specific observed effects. Theoretical work relating crack density and crack geometry to material modulus reduction [ $O^{\prime}$ Connell and Budiansky, 1974; Walsh, 1965; Zimmerman and King, 1985] and more recent work relating crack density to material strength reduction [Ashby and Sammis, 1990; Horaii and Ncmat-Nasser, 1986; Sammis and Ashby, 1986] suggest that it will be possible to obtain a complete and testable theory of shock wave damage in rock. Previous work by Hadley [1976] generally confirmed the O'Connell and Budiansky [1974] theory relating modulus reduction to microcrack production in quasi-statically deformed rock. The recognition by Simmons et al. [1973] that the seismic velocity reduction within the upper crust of the Moon was due to impact-generated cracking is but one example of the numerous instances in which velocity reduction can be used as a measure of impact-induced damage in rock. This report describes our initial laboratory study of this phenomenon. It is the first quantitative laboratory study of elastic modulus degradation in shocked rock. First, we discuss planar impact (one-dimensional) and then axisymmetric small-scale cratering experiments on rock. Then, we investigate the relationship of the measured crack damage parameters 
observed in the planar impact experiments to the observed rock damage versus distance from the crater in the axisymmetric experiments. The following strategy is employed:

1. Cracking during the complex loading and unloading history in the axisymmetric impact experiments could be a result of both the tensile stress concentration around flaws during the compressive pulse, and the tensile portion of the stress wave. Therefore, to better understand the underlying physics of rock failure, we have performed a series of oneclimensional tensile (spall) experiments on Bedford limestone to characterize the high-strain rate tensile strength properties of this material. A summary of some of these results are recently published [Rubin and Ahrens, 1991]. Our strategy was to shock discs of limestone at controlled stress magnitudes and durations below that required to produce complete spalling and to observe the progression in rock damage. The elastic moduli of the recovered samples were determined by measuring their longitudinal and shear wave velocities. As in the three-dimensional experiments, the seismic velocity deficits can be used to infer the crack densities that were induced as a function of applied stress and stress duration.

2. Experimental studies of crack density and modulus reduction produced by hemispherical shock waves in rock were carried out by impacting blocks of Bedford limestone and San Marcos gabbro with high-velocity projectiles. Longitudinal elastic wave ( $P$ wave) velocity measurements were carried out on a large number of oriented cubes cut out of each rock sample. Theoretical estimates of seismic velocity reductions based on microscopic observations of crack density are compared to observed velocity reductions for $P$ waves.

3. We relate the measured seismic velocity reductions in the axisymmetric experiments to the rock damage parameters of O'Connell and Budiansky [1974] and Grady and Kipp [1979, 1987]. The inferred damage parameter is then interpreted in light of estimates of the stress history of the samples using rock fracture properties derived from the planar impact experiments. We also examined the applicability of the theoretical and experimental analysis of the relation of fracture length induced by static indention into hard brittle media outlined by [Anstis et al., 1981] to the size of the zone of dynamic fragmentation.

\section{DYNAMIC ONE-DIMENSIONAL LOADING AND FRACTURE OF ROCK}

The dynamic tensile strength of rock can exceed the quasistatic tensile strength by an order of magnitude [Rinehart, 1965]. By "dynamic tensile strength" we mean the peak transient stress sustained during high strain rate tensile failure. The difference between dynamic and quasi-static (hereafter termed static) tensile failure results from the pristine rock containing abundant inherent flaws (pores, grain boundary cracks, etc.). If a tensile strain (stress) is increased gradually, the largest well-oriented flaw grows at the expense of others (Figure 1a). A characteristic "tensile strength" implies that the material has a characteristic largest flaw size. If the strain (stress) is increased very rapidly, then a single flaw and the zone of reduced stress surrounding that flaw cannot propagate rapidly enough to prevent other smaller or poorly oriented flaws from later being activated (Figure $1 b$ ). Because both the crack growth rate and the expansion of the stress-relaxed zone are limited
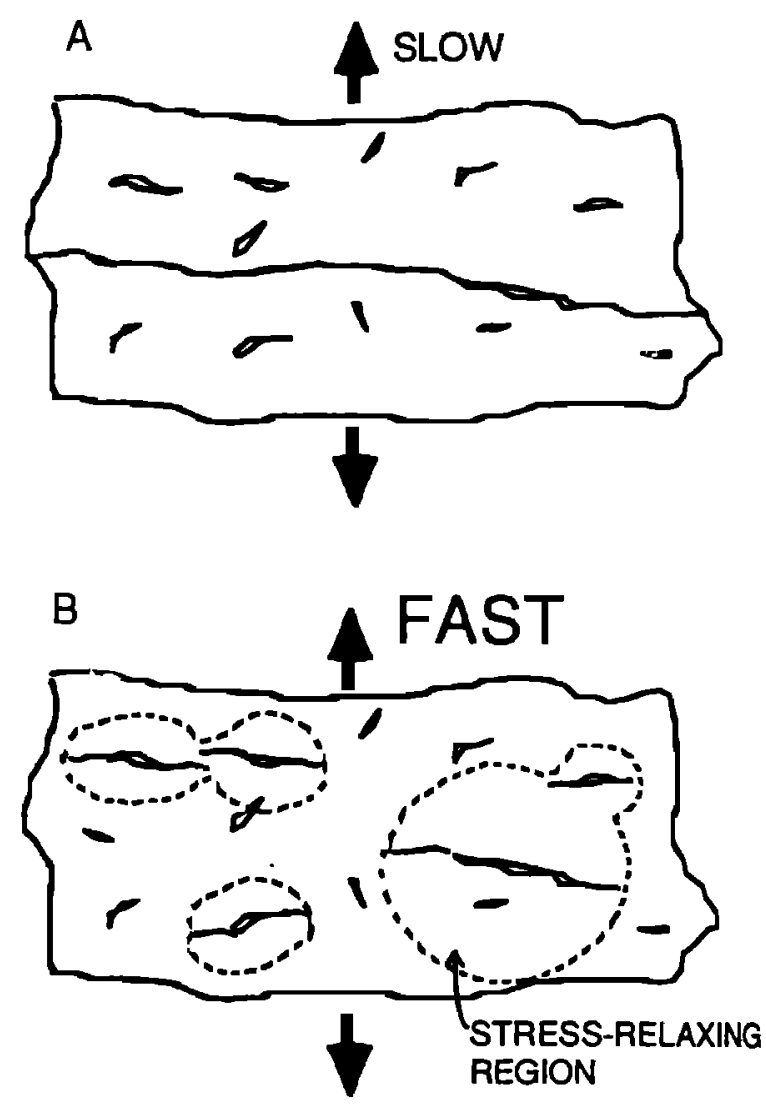

Fig. 1. Schematic diagram of tensile failure of rock under (a) quasistatic and (b) dynamic loads.

by the sound speed of the material, in general, the higher the strain rate, the smaller, at a given strain, the zone of reduced stress surrounding growing microcracks, the more flaws are activated and, ultimately, the greater the peak stress and number of fragments produced.

In current models of dynamic rock fracture [i.e., Grady and Kipp, 1987], the reduction in elastic modulus concurrent with microcrack growth is an essential element in describing the deformation history. For an elastic solid, the stress is equal to the product of the strain and the modulus. In a fragmenting solid, the stress history is determined by the competition between the increasing strain produced by the loading system, and the decreasing modulus produced by crack growth. Models incorporating this concept, combined with estimates of the initial flaw distribution from microscopy, have been used to explain the fragment size distribution and measured stress history within Arkansas novaculite in dynamic spall experiments [Grady and Kipp, 1987; Shockey et al., 1974]. However, there is ample reason to test the models further. For example, although during dynamic fragmentation the stress field is very heterogeneous, with some regions as yet unaffected by crack growth (Figure $1 b$ ), the computed stress is some average based on the effect of crack growth on the overall reduction in static modulus of the aggregate. Furthermore, although the experimental results are apparently consistent with static measurements of the rock fracture toughness [Grady and $K i p P$, 1987], they have yet to be reconciled with measurements of the much lower "apparent" fracture toughness of "subsize" cracks [Ingraffea, 1987], of which inherent flaws are examples. 


\section{EXPERIMENTAL PT.OCEDURE FOR PLANAR IMPACT EXPERIMENTS}

The purpose of the present experiments was to determine the modulus reduction of intact dynamically loaded rock samples at various stages of crack growth. This was accomplished by (1) loading the samples with tensile stress pulses of controlled magnitude and duration insufficient to cause complete spalling, and (2) measuring the subsequent reduction in $P$ and $S$ wave velocity due to microcracking.

Planar impact experiments used to produce dynamic tensile failure are described by Cohn and Ahrens [1981]. Briefly, a lexan projectile with a polymethyl methacrylate (PMMA) or aluminum (Al) flyer plate is accelerated to velocities of 10 to $25 \mathrm{~m} / \mathrm{s}$. The flyer plate impacts the target, which then flies free into a recovery tank, where loose rags prevent further damage. The target, a disc of rock $25 \mathrm{~mm}$ in diameter and 6.5 to $7.5 \mathrm{~mm}$ thick, is polished so that its front and rear surfaces are flat and parallel to \pm 0.005 $\mathrm{mm}$. The rock selected for this study, Bedford limestone, has been the subject of numerous rock mechanics investigations (Table 1).

Upon impact, compressive waves propagate forward into the target and back into the flyer plate. Tension is produced when these compressive waves, reflected as release waves from the free surfaces of the target and flyer plate, later meet within the sample. The magnitude of compressive stress is proportional to the impact velocity. For the PMMA experiments, separation occurs between the flyer plate and rock target, and the tension is equal in magnitude to the initial compression. For the Al experiments, a small residual compression is maintained across the flyer plate/rock interface, and the magnitude of tension is reduced by that amount (see below). The duration of the tensile pulse, if failure does not occur, is equal to the time required for the stress wave to traverse the flyer plate twice $(1.3 \mu \mathrm{s}$ for the PMMA and $0.5 \mu \mathrm{s}$ for the Al experiments). The magnitude of the tensile stresses, $\sigma$, quoted in Table 2 were calculated using the values of density $\rho$ and longitudinal wave velocity $C_{\mathrm{p}}$ from Table 1 .

Following impact, the particle velocity $u_{i}$ within the impactor can be derived from continuity of stress and displacement at the impactor/target interface [Cohn and Ahrcns, 1981]; the result is

$$
u_{i}=U_{p} \frac{\rho_{i C_{i}}}{\rho_{i} C_{i}+\rho_{t} C_{t}}
$$

Ilere $U_{p}$ is the projectile velocity, and the subscripts $i$ and $t$ refer to the impactor and target, respectively. The particle velocity within the impactor with respect to the projectile velocity, $U_{i}-U_{p}$, doubles upon initiation of the release wave from the rear of the flyer plate; the particle velocity behind the release wave front is then given by

$$
u_{i}=-U_{p}\left(1-\frac{2 \rho_{i} C_{i}}{\rho_{i} C_{i}+\rho_{t} C_{t}}\right) .
$$

This velocity is less than zero (opposite to $U_{p}$ ) if the impedance of the impactor is less than that of the target, equal to zero if the two impedances are equal, and greater than zero if the impactor impedance is greater than that of the target. Within the target, on the other hand, relaxation of the stress at the target/flyer interface to zero behind the release wave implies that the target particle velocity returns to zero. This implies that, when the impactor impedance is less than the target impedance, separation of the target and flyer plate occurs. In this case, the subsequent tensile stress within the target is given by the acoustic formula [Cohn and Ahrens, 1981]

$$
\sigma=U_{p} \frac{\rho_{t} C_{t} \rho_{i} C_{i}}{\rho_{i} C_{i}+\rho_{t} C_{t}}
$$

However, when $u_{i}$ within the impactor is greater than zero following release, then separation does not occur. In this case, there is a residual compression across the interface that can be determined by treating the positive impactor particle velocity behind the release wave front as if it were a (zero pressure) projectile moving with that velocity; that is, by substituting $u_{i}$ behind the release wave for $U_{p}$ in equation (1a). The peak tension later reached within the sample is reduced by this amount, yielding

$$
\sigma=U_{p} \frac{\rho_{t} C_{t} \rho_{i} C_{i}}{\rho_{i} C_{i}+\rho_{t} C_{t}}\left(2-\frac{2 \rho_{i} C_{i}}{\rho_{i} C_{i}+\rho_{t} C_{t}}\right)
$$

Equation (1a) is used for the PMMA flyer plate experiments and $(1 b$ ) for the $\mathrm{Al}$ experiments.

TABLE 1. Physical Properties of Experimental Materials

\begin{tabular}{lccccc}
\hline Material & $0 . \mathrm{g} / \mathrm{cm}^{3}$ & $\mathrm{C}_{\mathrm{m} m} \mathrm{~km} / \mathrm{s}$ & $\mathrm{C} . \mathrm{km} / \mathrm{s}$ & $\mathrm{E}, \mathrm{GPa}$ & OT, MPa \\
\hline $\begin{array}{l}\text { Bedford } \\
\text { limestone } \\
\text { (dry) }\end{array}$ & $2.42(1)$ & $4.9(1)$ & $2.8(1)$ & $\begin{array}{l}48(1), \\
24(2),\end{array}$ & $\begin{array}{l}5.4(2) \\
0.8-1.2(4), \\
7.7(5)\end{array}$ \\
$\begin{array}{l}\text { Bedford } \\
\text { limestone } \\
\text { (saturated) }\end{array}$ & $2.53(1)$ & $5.1(1)$ & & & \\
$\begin{array}{l}\text { PMMA } \\
\text { Aluminum }\end{array}$ & 1.2 & 2.8 & & \\
\hline
\end{tabular}

Sources: (1) this study, (2) Nur and Simmons [1969 ], (3) Schmidt [1976], (4) Ingraffea et al. [1984], (5) Ingraffea
and Schmidt, [1978]. 
TABLE 2. One-Dimensional Tensile Strain Impact Parameters and Preshot and Postshot Ultrasonic Compressional and Shear Velocities

\begin{tabular}{|c|c|c|c|c|c|c|c|c|c|}
\hline \multirow[t]{2}{*}{ Shot } & \multirow[t]{2}{*}{ Sample } & \multirow{2}{*}{$\begin{array}{l}\text { Flyer } \\
\text { Plate }\end{array}$} & \multirow[t]{2}{*}{ Atmosphere } & \multirow{2}{*}{$\begin{array}{c}\text { Projectile } \\
\text { Velocity, } \\
\mathrm{m} / \mathrm{s}\end{array}$} & \multirow{2}{*}{$\begin{array}{c}\text { Tensile } \\
\text { Stress, } \\
\text { MPa } \\
\end{array}$} & \multicolumn{2}{|c|}{ Preshot } & \multicolumn{2}{|c|}{ Postshot } \\
\hline & & & & & & $C_{p}, \mathbf{k m} / \mathbf{s}$ & $C_{\mathrm{s},} \mathrm{km} / \mathrm{s}$ & $C_{p,} \mathrm{~km} / \mathrm{s}$ & $C_{s,} \mathrm{~km} / \mathrm{s}$ \\
\hline 1 & BL \#2 & PMMA & air & 24.0 & 62.4 & 4.88 & 2.91 & 4.34 & 269 \\
\hline 2 & BL\#3 & PMMA & air & 16.9 & 43.9 & 4.38 & 2.68 & 4.9 & 2.92 \\
\hline 3 & BL\#4 & PMMA & air & 20.6 & 53.6 & 4.55 & 2.76 & $\begin{array}{l}4.09 \\
3.84^{a} \\
3.79^{a}\end{array}$ & $\begin{array}{l}2.58 \\
2.46 \\
2.44\end{array}$ \\
\hline 4 & BL\#10 & PMMA & air & 16.3 & 42.4 & 4.25 & 2.74 & 4.22 & 2.68 \\
\hline 5 & BL\#11 & PMMA & air & 22.5 & 53.5 & 4.42 & 2.81 & $\begin{array}{l}3.74 \\
3.87 \\
3.87\end{array}$ & $\begin{array}{l}2.48 \\
2.24 \\
2.54\end{array}$ \\
\hline $\begin{array}{l}7 \\
8\end{array}$ & $\begin{array}{l}\text { BL\#5 } \\
\text { BL\#7 }\end{array}$ & $\begin{array}{l}\text { PMMA } \\
\text { PMMA }\end{array}$ & $\begin{array}{l}\text { vacuum } \\
\text { vacuum }\end{array}$ & $\begin{array}{l}24.7 \\
26.5\end{array}$ & $\begin{array}{l}64.2 \\
58.9\end{array}$ & 4.65 & 2.84 & $\underset{b}{4.26}$ & $\frac{2.63}{b}$ \\
\hline 9 & BL\#8 & PMMA & vacuum & 24.2 & 62.9 & 4.3 & 2.74 & 3.33 & 2.17 \\
\hline 10 & BL\#9 & PMMA & vacuum & 22.6 & 58.8 & 4.3 & 2.74 & 4.17 & 2.58 \\
\hline 11 & BL101 & PMMA & vacuum & 12.53 & 32.6 & 4.59 & 2.82 & 4.67 & 2.84 \\
\hline 12 & BL102 & PMMA & vacuum & 22.88 & 595 & & & $b$ & $b$ \\
\hline 13 & BL103 & PMMA & vacuum & 16.61 & 43.2 & 4.71 & 2.77 & 4.36 & 2.55 \\
\hline 15 & BL106 & PMMA & vacuum & 22.14 & 57.6 & 4.70 & 2.78 & $\begin{array}{l}4.33 \\
4.1\end{array}$ & $\begin{array}{l}2.43 \\
2.46\end{array}$ \\
\hline 16 & BL107 & $\begin{array}{c}\text { PMMA } \\
\mathrm{Al}\end{array}$ & vacuum & $\begin{array}{l}18.45 \\
24.6\end{array}$ & $\begin{array}{r}48.0 \\
139.5\end{array}$ & 4.69 & 2.85 & $\begin{array}{c}4.42 \\
b\end{array}$ & 2.60 \\
\hline $\begin{array}{l}18 \\
19\end{array}$ & BL\#16 & Al & vacuum & $\begin{array}{l}24.6 \\
19.8\end{array}$ & $\begin{array}{l}139.5 \\
112.5\end{array}$ & $\begin{array}{l}4.17 \\
4.17\end{array}$ & $\begin{array}{l}2.71 \\
2.73\end{array}$ & 3.58 & 2.35 \\
\hline & & & & & & & & 3.50 & 2.40 \\
\hline 20 & BL\#17 & Al & vacuum & 17.8 & 101.1 & 4.5 & 2.83 & $\begin{array}{l}4.02 \\
3.60\end{array}$ & $\begin{array}{l}2.42 \\
2.48\end{array}$ \\
\hline 21 & BL\#18 & $\mathrm{Al}$ & vacuum & 12.6 & 71.6 & 4.32 & 2.82 & 4.56 & 2.81 \\
\hline 22 & BL\#19 & Al & vacuum & 15.0 & 85.2 & 4.35 & 2.84 & 3.79 & 2.58 \\
\hline 23 & BL\#21 & Al & vacuum & 20.9 & 113.6 & 4.49 & 2.90 & $c$ & c \\
\hline 24 & BL\#22 & Al & vacuum & 17.2 & 97.7 & 4.62 & 2.82 & 4.40 & 267 \\
\hline 25 & BL\#12 & Al & air & 11.19 & 63.6 & 4.39 & 2.82 & 4.24 & 2.73 \\
\hline 26 & BL\#13 & Al & air & 22.2 & 126.1 & 4.34 & 2.79 & $\begin{array}{l}3.29 \\
3.61\end{array}$ & $\begin{array}{l}2.20 \\
2.31\end{array}$ \\
\hline & & & & & & & & 3.42 & 206 \\
\hline 27 & BL\#14 & Al & air & 25.8 & 146.6 & 4.37 & 2.78 & 3.26 & 1.88 \\
\hline 28 & BL\#20 & Al & air & 19.35 & 109.9 & 4.41 & 2.78 & & \\
\hline 29 & BL201 & Al & air & 19.2 & 109.0 & 4.84 & 2.72 & $\begin{array}{l}4.41 \\
4.63 \\
4.38\end{array}$ & $\begin{array}{l}2.49 \\
2.68 \\
2.47\end{array}$ \\
\hline 30 & $\mathrm{BL} 202$ & Al & air & 12.9 & 73.3 & 4.65 & 2.74 & 4.42 & 2.55 \\
\hline 31 & BL203 & Al & air & 15.56 & 88.4 & 4.98 & 2.72 & 4.35 & 2.55 \\
\hline 32 & BL211 & $\mathrm{Al}$ & air & 10.85 & 61.6 & & 2.73 & 4.81 & 2.70 \\
\hline 33 & BL109 & Al & vacuum & 22.06 & 126.3 & 4.63 & 2.75 & 4.06 & 2.63 \\
\hline & & & & & & 4.63 & 2.74 & $\begin{array}{l}3.90 \\
4.01\end{array}$ & $\begin{array}{l}2.50 \\
2.69\end{array}$ \\
\hline 34 & BL110 & Al & vacuum & 24.45 & 138.9 & 4.61 & 2.77 & $\begin{array}{l}3.82 \\
4.03\end{array}$ & $\begin{array}{l}2.57 \\
2.65\end{array}$ \\
\hline & & & & & & & & 4.01 & 2.59 \\
\hline 35 & BL212 & Al & air & 16.07 & 91.3 & 4.69 & 2.80 & 4.72 & 2.70 \\
\hline 36 & BL2099 & $\mathrm{Al}$ & air & 16.20 & 103.3 & $\begin{array}{l}4.86 \\
4.66\end{array}$ & 2.80 & 4.72 & 2.73 \\
\hline & $\mathrm{w}^{d}$ & & & & & 4.70 & $\begin{array}{l}2.77 \\
2.77\end{array}$ & $\begin{array}{l}4.60 \\
4.73\end{array}$ & $\begin{array}{l}2.76 \\
2.76\end{array}$ \\
\hline 37 & $\begin{array}{l}\text { BL207 } \\
\text { We }^{e}\end{array}$ & Al & air & 21.89 & 139.5 & $\begin{array}{l}4.69 \\
4.84\end{array}$ & $\begin{array}{l}2.80 \\
2.80\end{array}$ & $\begin{array}{l}4.89 \\
4.69\end{array}$ & $\begin{array}{l}2.82 \\
2.72\end{array}$ \\
\hline 38 & $\underset{\mathrm{W}}{\mathrm{BL} 210}$ & $\mathrm{Al}$ & air & 10.85 & 69.2 & 4.74 & & & \\
\hline 39 & $\underset{W}{\text { BL204 }}$ & Al & ajr & 13.4 & 85.4 & 4.69 & 2.68 & 4.39 & 2.55 \\
\hline 40 & $\underset{W}{\text { BL205 }}$ & Al & air & 15.08 & 96.2 & 4.82 & & 4.4 & 2.54 \\
\hline 41 & $\begin{array}{c}\text { BL206 } \\
\mathrm{w}^{e}\end{array}$ & Al & air & 19.34 & 123.3 & 4.94 & 2.72 & 4.26 & 2.32 \\
\hline 42 & $\begin{array}{c}\text { BL208 } \\
\mathrm{W}^{e}\end{array}$ & $\mathbf{A} \mathbf{l}$ & air & 25.80 & 164.5 & 4.80 & & $\begin{array}{l}4.64 \\
4.77 \\
\end{array}$ & $\begin{array}{l}2.68 \\
2.67 \\
\end{array}$ \\
\hline
\end{tabular}

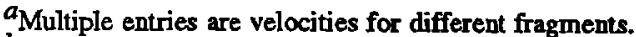

${ }^{b}$ Sample too heavily damaged via spelling to conduct postshot velocity measurements.

'Sample too damaged via radial cracks for measurements.

${ }^{d} \mathrm{~W}$ designates water-saturated sample.

eAluminum ring placed around sample prior to firing to prevent radial cracking. This ring apparently precorapressed sample and inhibited cracking; hepce data are not shown in Figures 2 and 4. 
Several assumptions are made in computing the magnitude and duration of the tensile pulse. (1) Because rocks are generally much stronger in compression than tension, no damage occurs during the initial compressive pulse. (2) The $P$ wave velocity is constant over the pressure range involved (several tens of megapascals). (3) The rise time of the stress pulse is much shorter than its duration. (4) The strain can be considered to be one-dimensional. (5) Negligible crack growth occurs during later reverberations of the stress waves. These assumptions are discussed further below.

In order to determine the effect of pore water on dynamic fracture behavior, four shots were performed on watersaturated samples. The samples were evacuated overnight, and water was siphoned into the container before the samples were exposed to atmosphere. The front and rear surfaces of the targets were covered with a cellophane tape $<0.02 \mathrm{~mm}$ thick to prevent evaporation. The perimeters of the targets were likewise covered, except for a several $\mathrm{mm}$ gap at the top where a large drop of water was held by surface tension as they were mounted and shot. Approximately 5-7 min were required to mount, align, and shoot the targets. Evaporative weight loss within the sample in this time was determined to be less than $1 \%$ of the total water content without the buffering water droplet. The sound speed measurements on these saturated samples made prior to and following impact were performed dry. Four shots were also performed on dry, taped targets, which demonstrated no detectable effect due to the tape alone.

The Bedford limestone specimens used have a typical grain size of $0.5 \mathrm{~mm}$ and a porosity of $\sim 9.9 \%$ (Table 1 ), Ultrasonic velocities (reproducible to $<2 \%$ ) were measured using the travel-time method with $1 \mathrm{MHz}$ PZT transducers. The dry velocities are higher than those of Nur and Simmons [1969], and the difference between the wet and dry velocity is less. This suggests a lower pore volume in the form of high aspect ratio cracks [Toksöz et al., 1976]. Table 1 also gives previous determinations of the static tensile strength $\sigma$, fracture toughness $\mathbf{K}_{\mathbf{I c}}$, and Young's modulus $\mathbf{E}$.

\section{RESULTS FOR PLANE IMPACT EXPERIMENTS}

The results of the ultrasonic velocity measurements are shown in Table 2 and Figure 2. Both longitudinal and shear wave velocities in the direction perpendicular to the impact surface were measured, and compared to the preshot velocities. Two typical samples are shown in Figure 3. Important points are as follows:

1. Comparable levels of rock damage occur at considerably lower stresses in the longer-duration experiments. The onset of microcrack growth, as determined by a detectable reduction in sound velocity, occurs at computed stresses of - 60 and $-35 \mathrm{MPa}$ in the 0.5- and 1.3$\mu s$ experiments. Complete spalling occurs above computed stresses of -135 and $60 \mathrm{MPa}$ in the $0.5-$ and $1.3-\mu \mathrm{s}$ experiments.

2. Macroscopic radial cracks were produced above computed stresses of -100 and $45 \mathrm{MPa}$ in the 0.5- and 1.3$\mu s$ experiments, indicating that strain was not completely one-dimensional as assumed. Such radial cracks commonly plague planar-impact recovery experiments [Shockey et al., 1974].

3. Comparable velocity reductions occur for both longitudinal and shear waves.

4. The results for the four water-saturated targets are indistinguishable from those for the dry targets. (The experiments which used aluminum constraining rings are not considered in this comparison.)
In order to relate the velocity deficits observed in the one-dimensional experiments to three-dimensional impact experiments, it is useful to utilize the damage parameters, $D_{p}$ and $D_{s}$ (Figure 4) which are defined as

$$
\begin{aligned}
& D_{p}=1-\left(C_{p} / C_{p o}\right)^{2} \\
& D_{s}=1-\left(C_{s} / C_{s o}\right)^{2}
\end{aligned}
$$

where $C_{p}$ and $C_{s}$ are longitudinal and shear wave velocity, and the subscript zero indicates the undamaged value. As is evident in both Figures 2 and 4, for a given tensile stress, a range of damage is demonstrated by different samples.

\section{Intcrpretation of the Velocity Reduction Data}

The $P$ wave velocity of the starting material was $75 \%$ of that reported by Christensen [1982] for an aggregate of calcite crystals. Assuming a random distribution of pennyshaped cracks, this implies an initial crack density, $\varepsilon$, of 0.2 , where crack density is expressed as

$$
\varepsilon=N\left\langle a^{3}\right\rangle
$$

where $\mathrm{N}$ is the number of cracks per unit volume and $\left\langle\mathrm{a}^{3}\right\rangle$ is the average of the cube of the crack radii [ $O^{\prime}$ Connell and Budiansky, 1974]. A 2\% reduction in $\mathrm{P}$ wave velocity corresponds to an increase in crack density of 0.016 , or about a $3 \%$ increase in the radii of the largest cracks present, so this growth represents the minimum that could be detected by the present method.

\section{Onset of Tensile Cracking}

Following Grady and Kipp [1987], we use a simple model for the time-dependent stress intensity factor at the tips of inherent flaws to compute an apparent fracture toughness appropriate for the dynamic loading conditions of the experiments. The assumption is that crack growth occurs when the crack tip stress intensity factor $K_{I}$ equals the rock fracture toughness $K_{I c}$ - Under a static applied tension $\sigma$, for an isolated penny-shaped crack of radius a,

$$
K_{I}=2 \sigma \sqrt{a / \pi}
$$

Under dynamic loading conditions the form of the equation remains the same, but for early time, the "effective" crack size grows as $\mathrm{C}_{\mathrm{g}} \mathrm{t}$ :

$$
K_{I}-2 \sigma \sqrt{C_{s} t / \pi}, \quad C_{s} t<a .
$$

These considerations imply that for suddenly applied loads of a prescribed duration $t$, there is some critical tension $\sigma$ above which $K_{I}>K_{I c}$, given sufficiently large cracks (of radius $\left.a>C_{s} t\right)$. Substituting into $(4 b)$ the stress at the onset of microcracking for $\sigma$, the duration of the tensile pulse for $t$, and the value of $\mathrm{C}_{\mathbf{s}}$ for Bedford limestone, we compute $\mathrm{K}_{\mathrm{Ic}}\left(\mathrm{K}_{\mathrm{I}}\right.$ at the onset of microcracking) to be 2.4 and $2.5 \mathrm{MPa} \mathrm{m} / 1 / 2$ for the $1.3-$ and $0.5-\mu \mathrm{s}$ experiments, respectively. This is 2 to 3 times the 0.8 to $1.2 \mathrm{MPa} \mathrm{m}^{1 / 2}$ reported by Ingraffea [1987] for Indiana limestone under static loading. The flaws activated are those with radius a > $C_{s} t$, or 3.6 and $1.4 \mathrm{~mm}$ for the 1.3- and 0.5- $\mu \mathrm{s}$ experiments. Although a flaw diameter of $2.8 \mathrm{~mm}$ is smaller than the largest grains in Indiana limestone $(3 \mathrm{~mm}$ according to 


\section{Al Flyer Plates ( $0.5 \mu s$ Duration)}
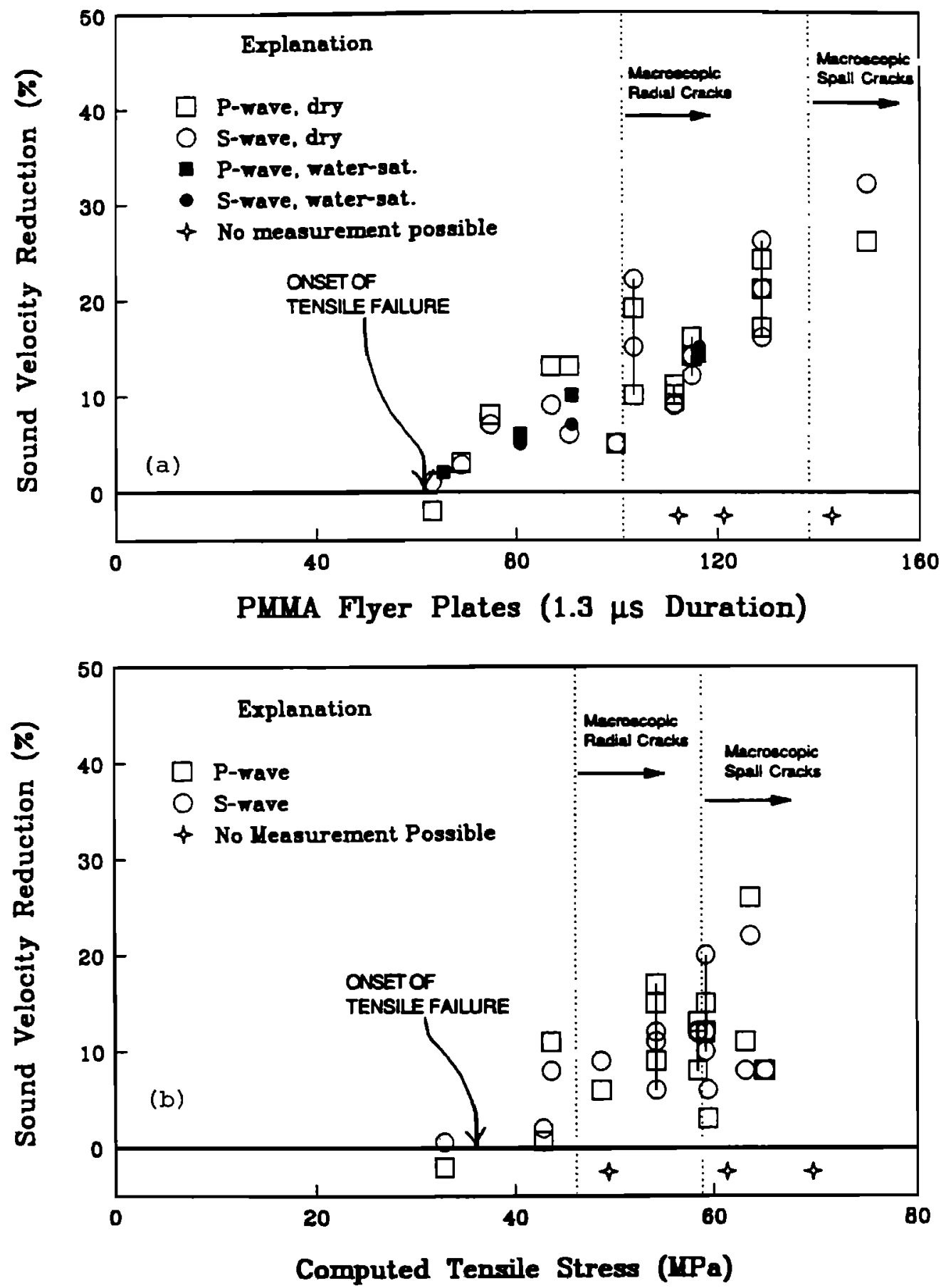

Fig. 2. Velocity measurements for (a) $0.5 \mu s$ and (b) 1.3 Hs experiments. Dashed lines indicate pressures above which macroscopic radial and impact-face-parallel (spall) cracks occurred. Vertical bars connect measurements made on different pieces of targets broken by radial cracke.

Ingraffea and Schmidt [1978]), $7.2 \mathrm{~mm}$ is clearly much larger than the largest grains present.

Grady and Kipp [1987] interpret dynamic spall data and the size of the largest flaws observed in the samples for several rocks as consistent with crack growth from initial flaws at values of $K_{I}$ equal to the statically determined fracture toughness. We identify two possible ways to relate the fracture toughness and initial flaw size from the present data to the static fracture toughness and grain size of Bedford limestone:
1. The computed magnitude and/or duration of the tensile loads could be overestimates. Grady and Kipp [1987] found typical strain rates in plate impact experiments to be $10^{4} / \mathrm{s}$. For the current Young's modulus, this would produce stresses of $60 \mathrm{MPa}$ in $0.125 \mu \mathrm{s}$. However, wave scattering due to the large porosity and grain size (1/5 of the tensile pulse wavelength for the $0.5-\mu$ s experiments) could produce further spreading of the wave front and attenuation of the peak stress. This possibility could be tested by obtaining particle velocity profiles at the back of the target [i.e., Grady and 

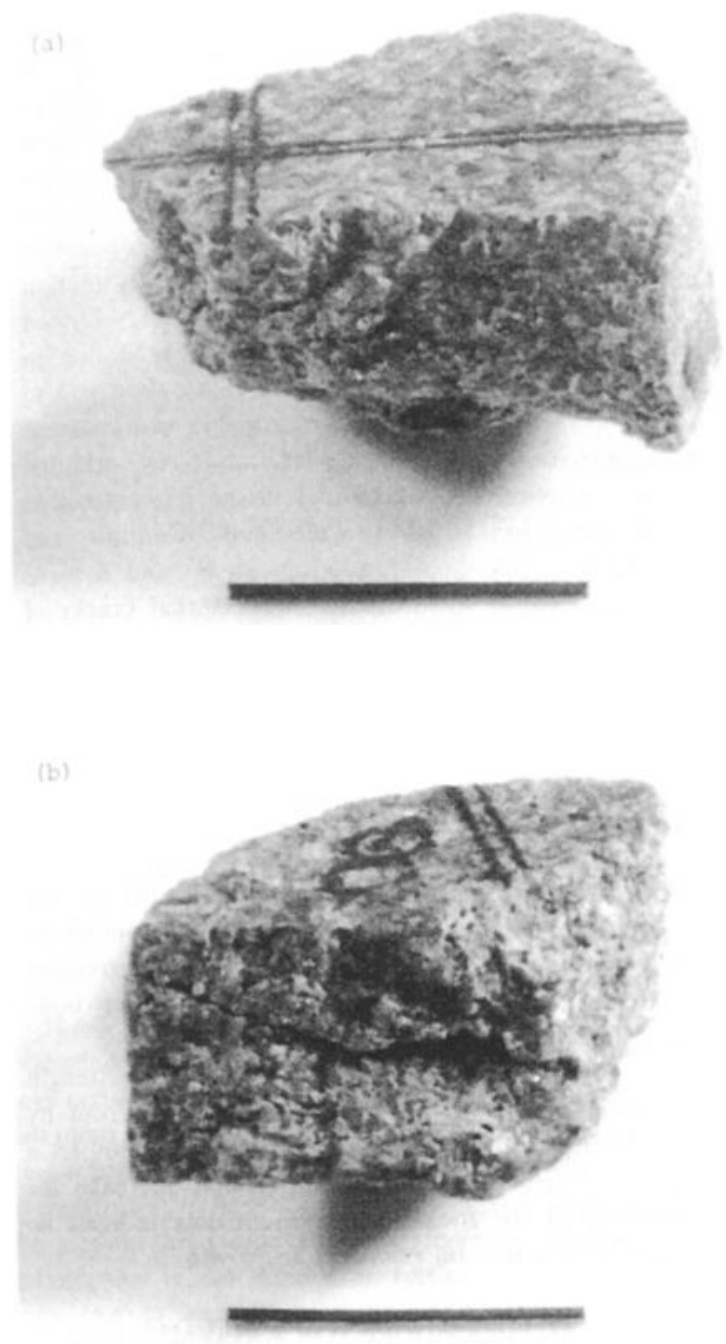

Fig. 3. Recovered fragments (a) and (b) of sample 8 impacted at $24 \mathrm{~m} / \mathrm{s}$ with a PMMA impactor. Horizontal cracks are incipient spall cracks. Wire in photo is $0.5 \mathrm{~mm}$ in diameter and $1.0 \mathrm{~cm}$ long. The measured velocity recuction was 23 and $21 \%$ for $P$ and $S$ waves.

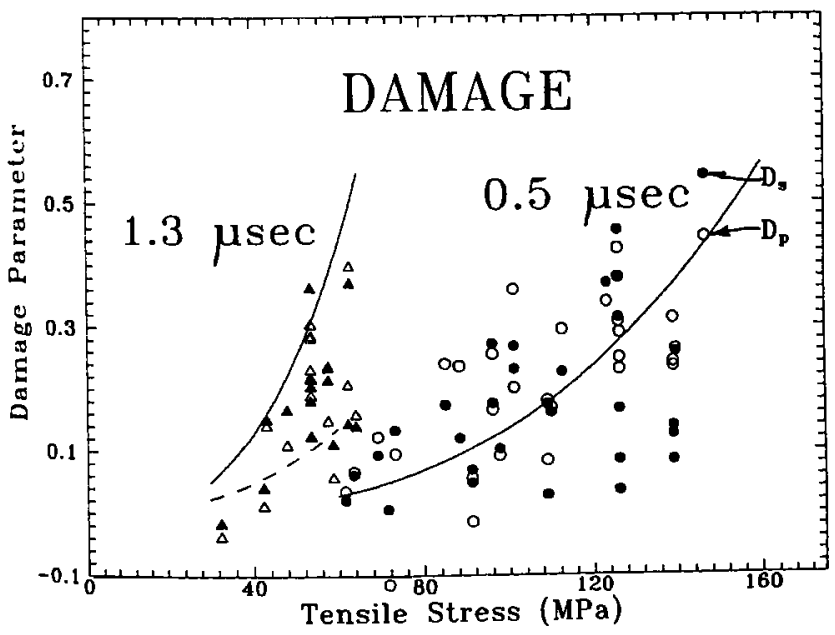

Fig. 4. Damage parameters $D_{p}$ and $D_{s}$ versus dynamic tensile stress. Curves indicating maximum damage at a given tensile stress for 0.5 - and 1.3- $\mu$ s duration experiments are given by $D=1.37 \times 10^{-7} \sigma^{3}$ and $D=2$ $x 10^{-6} \sigma^{3}$ where $\sigma$ is in megapascals. Note that dependence with stress $\propto$ to $\sigma^{3}$ is indicated by data. The dashed curve has a $\sigma^{2.5}$ dependence.
Kipp, 1979]. We note that Grady and Kipp [1987] obtained $-20 \mathrm{MPa}$ as the dynamic tensile strength at a nominal strain rate of $10^{4} / \mathrm{sec}$ in Indiana limestone, which is close to that observed here $(-30 \mathrm{MPa})$ for the onset of cracking at a nominal stress duration of $1.3 \mu \mathrm{s}$.

2. The interaction of several closely spaced flaws could be critical in the initiation of tensile failure. Under static loading conditions, the stress intensity factors at the tips of closely spaced cracks can be much larger than for the same size isolated cracks. Under dynamic loading conditions, the time required for the stress intensity factors to reach their static values would be much longer for interacting cracks than for isolated cracks. Thus at the lowest dynamic loads producing failure, the time to failure could be larger than $a_{\ell} C_{s}$ where a $\ell$ is the radius of the largest flaw. Microcrack interaction could play an essential role in both dynamic and static rock failure.

We believe that the discrepancy between the dynamic and static data remains even for those cases cited by Grady and Kipp [1987] where the stress history has been determined more directly. The reason is that for initial crack lengths below some critical value, the "apparent" fracture toughness determined from static experiments has been found to decrease with crack length (Figure 5). The critical half length is about $40 \mathrm{~mm}$ for Indiana limestone, and for half lengths of $5 \mathrm{~mm}$ the apparent fracture toughness is only 0.5 $\mathrm{MPa} \mathrm{m}^{1 / 2}$ [Ingraffea and Schmidt, 1978]. A static tensile strength of $6 \mathrm{MPa}$ would require an apparent fracture toughness as low as $0.26 \mathrm{MPa} \mathrm{m} \mathrm{m}^{1 / 2}$, if the fractures initiated from isolated flaws the size of the largest grains present. A similar relationship between crack size and apparent fracture toughness has been found for Westerly granite, a lowporosity crystalline rock [Ingraffea et al., 1984].

The size dependence of the apparent fracture toughness has been explained qualitatively as resulting when the zone of inelastic deformation at the crack tip becomes large with

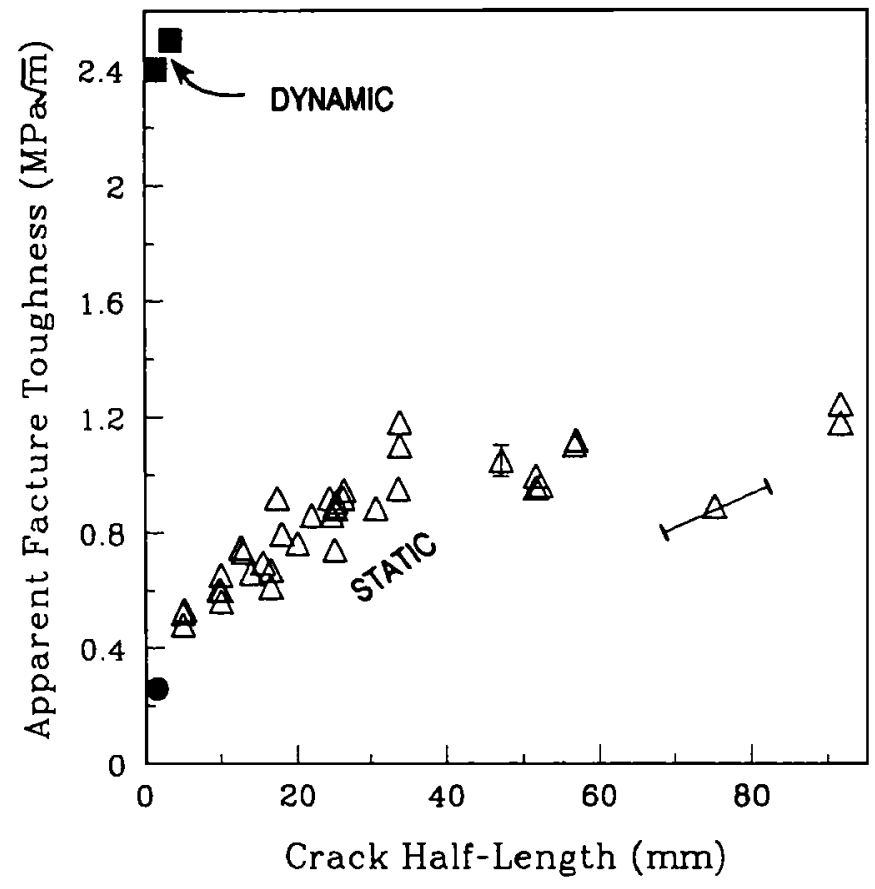

Fig. 5. Apparent quasi-static fracture toughness as a function of crack size in Bedford limestone (modified from [Ingraffea, 1987]). Bars give standard deviation of tests. Solid circle is from static tensile tests (tensile strength $6 \mathrm{MPa}$; isolated flaws of radius $1.5 \mathrm{~mm}$ ), squares are present data (plotted at computed minimum crack length). 
respect to the crack length. Under such conditions linear elastic fracture mechanics (LEFM) is inadequate for describing crack growth [Ingraffea, 1987]. Thus, although the dynamic data are apparently consistent with simple models assuming LEFM and values of $\mathrm{K}_{\mathrm{Ic}}$ appropriate for large cracks [Grady and Kipp, 1987], the same models do not adequately explain the static tensile strength of rock. Microcrack interaction therefore appears to be required to reconcile the dynamic and static fracture toughness data. Under static conditions, crack interactions lower the tensile stress required for failure, relative to the isolated crack case. Under dynamic loading conditions, at relatively low stress levels, interaction would still be required for failure, but would require longer initiation times than for the isolated crack case. At high dynamic stress levels, interaction might not be required, but failure would occur at higher values of $\mathrm{K}_{\mathrm{Ic}}$ than predicted, based on the static tensile strength assuming isolated cracks the size of the largest flaws observed.

\section{Increasing Rock Damage with Stress Level}

At higher tensile stress $\sigma, \mathbf{K}_{\mathbf{I}}$ reaches $\mathrm{K}_{\mathrm{Ic}}$ at earlier times $t_{c}$. Rewriting (4b), we obtain

$$
t_{c}=\pi K_{I c}^{2} /\left(4 C_{s} \sigma^{2}\right)
$$

for the time to growth. Therefore for larger $\sigma$, cracks will have a longer time in which to grow prior to the cessation of tension. In addition, crack growth at earlier times implies more cracks of radius a $>\mathrm{C}_{s} \mathrm{t}_{c}$, so mo:e cracks will be activated. Both these factors promote increasing crack density and ultimately complete spalling. Assuming an initial crack density of 0.2 , the measured $30 \%$ reduction in sound velocity prior to complete spalling corresponds approximately to an increase in crack density to 0.4 [O'Connell and Budiansky, 1974]. At crack densities above about 0.5 the O'Connell and Budiansky model predicts that the material quickly disaggregates with increasing damage, providing a plausible explanation for our detected maximum velocity reduction. Other models, however, predict non-zero moduli for all finite crack densities [e.g. Zimmerman and King, 1985]. Within the interval 0.2 to 0.4 the velocity reduction increases nearly linearly with crack density, so we interpret the data as indicating increases in crack density of $0.003 / \mathrm{MPa}$ and $0.007 / \mathrm{MPa}$ in the $0.5-$ and $1.3-\mu \mathrm{s}$ experiments, respectively.

The ultimate spall strength of $60 \mathrm{MPa}$ determined for the $1.3 \mu \mathrm{s}$ experiments is approximately 10 times the static tensile strength reported by Schmidt [1976], consistent with the ratio of dynamic and static strengths of other rocks. However, the amount by which the computed tensile stress exceeds the actual stress is expected to increase with impact velocity, as crack growth initiates and begins to relax the tension earlier.

\section{Radial Crack Growth and Subequal Reductions in Wave} Velocities $P$ and $S$

The radial cracks observed to form above threshold stress levels for each of the two series of experiments indicate that deformation was not restricted to uniaxial strain. The radial cracks may result from failure first occurring at the sample edge during the initial compression. The Hugoniot elastic limit, or dynamic compressive strength under conditions of uniaxial strain, is about $400 \mathrm{MPa}$ for Bedford limestone, well above the stresses achieved here [Ahrens and Gregson, 1964]. However, near the sample edges the rock is essentially unconfined, which lowers the compressive strength. A second possible source for the cracks is that bending moments result from the perimeter of the flyer plate being supported by the lexan projectile.

Aligned cracks are expected to produce a greater reduction in $P$ than $S$ wave velocity, for a propagation direction perpendicular to the crack planes. If all cracks formed parallel to the target impact surface, a 20\% reduction in longitudinal velocity would be associated with only a $\sim 5$ to $7 \%$ reduction in shear velocity, for reasonable crack aspect ratios [Anderson et al., 1974]. For randomly oriented cracks, a $20 \%$ reduction in longitudinal velocity is associated with an $18 \%$ reduction in shear velocity [ $O^{\prime}$ Connell and Budiansky, 1974]. Subequal reductions in $P$ and $S$ wave velocities in the current experiments suggest that cracks of diverse orientations have been produced, as opposed to the dominantly face-parallel spall cracks expected. Thus both radial and face-parallel cracks are apparently contributing to the measured velocity reductions.

\section{Effect of Water Saturation}

Water is known to play an important role in the compressive failure of rock under static loading conditions. It can also reduce the tensile strength by providing chemically reactive species to facilitate molecular bond breaking at crack tips.

The effect of pure water on the dynamic tensile strength of rock is unknown. It could steepen the wave front by reducing scattering, introduce viscous dissipation, impart a viscous suction to opening crack walls, and increase the dynamic modulus of the rock. The present data indicate no significant effect of water on microcrack growth.

\section{EXPERIMENTAL PROCEDURE FOR AXISYMMETRIC CRATERING EXPERIMENTS}

Samples of Bedford limestone from the same aliquot as the one-dimensional sample, and San Marcos gabbro, similar to that employed in previous studies [Lange et al., 1984; Polanskey and Ahrens, 1990], were acquired. The San Marcos gabbro specimen is a 20 -cm cube, with a density of $2.867 \mathrm{~g} / \mathrm{cm}^{3}$ and a very low initial crack density [Lange $e t$ al., 1984; Wong and Biegel, 1985]. It was impacted by a 3.2-mm-diameter steel projectile (mass $0.143 \mathrm{~g}$ ) at a speed of $5.2 \mathrm{~km} / \mathrm{s}$. The resulting crater is approximately $10 \mathrm{~cm}$ across and $1.0 \mathrm{~cm}$ deep. The upper $5 \mathrm{~cm}$ of the specimen was cut in half (Figure 6 ) and a 1-cm-thick section was cut from one of the halves. The half of this section corresponding to the left half of Figure 6 was cut into oriented $\sim 1-\mathrm{cm}$ cubes for $P$ wave velocity measurements. The impactor mass and velocity were chosen so as to produce a large crater compared to the size of the $1 \mathrm{~cm}$ cubes but small enough that large edge effects would not be produced by the target boundaries.

The shocked Bedford limestone specimen is a block, 20 $\mathrm{cm}$ on a side and $12 \mathrm{~cm}$ deep. The large rock sample has a bulk density of $2.62 \mathrm{~g} / \mathrm{cm}^{3}$, an average grain size of approximately $0.5 \mathrm{~mm}$, and a pore porosity of approximately 0.12 . Cracks, as opposed to pores, were not observed with an optical microscope. It was impacted by a 5.6-mm-diameter copper-jacketed lead bullet (mass $3.2 \mathrm{~g}$ ) at a speed of $1.2 \mathrm{~km} / \mathrm{s}$. The upper $6.8 \mathrm{~cm}$ of the sample was cut in half in order to prepare oriented cubes as for the gabbro. 


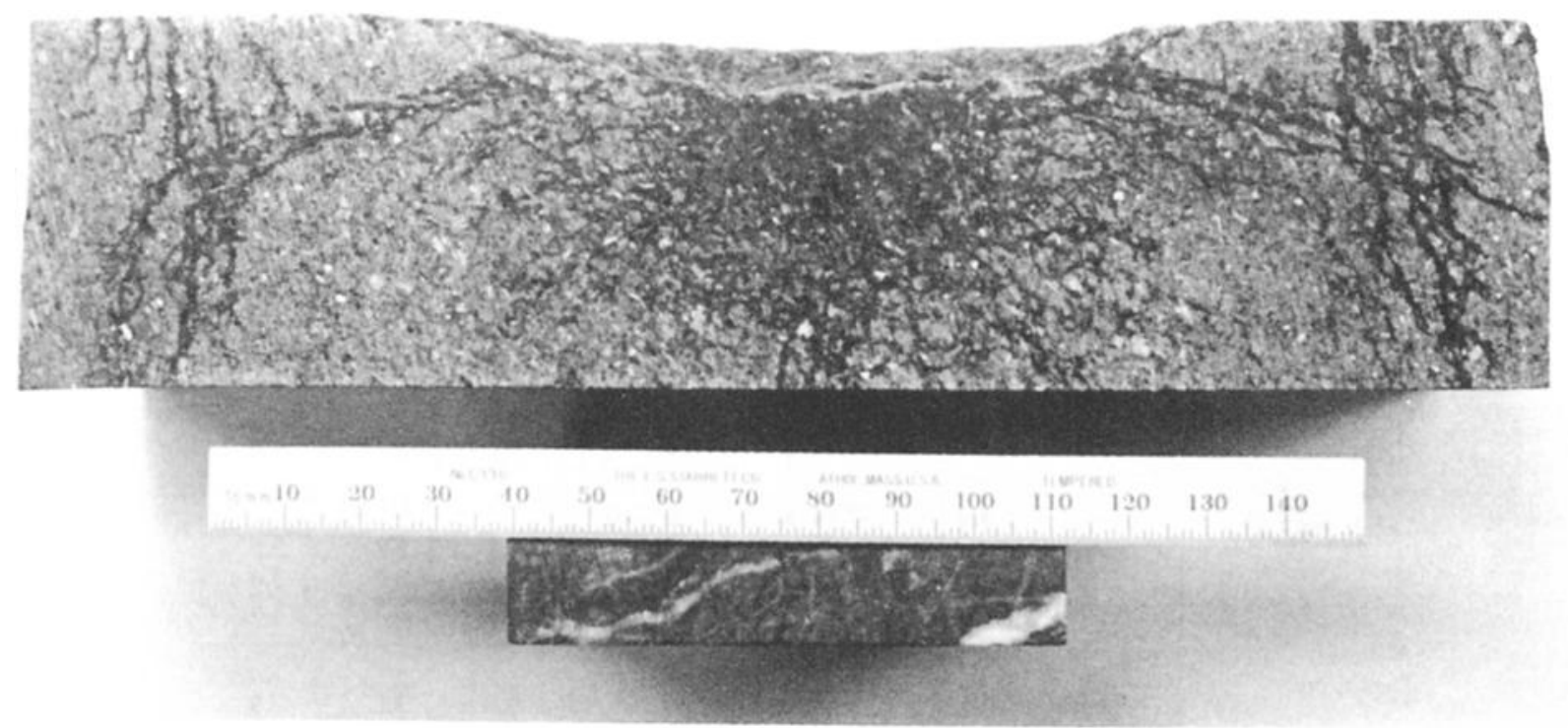

Fig. 6a. Cross section of shocked San Marcos gabbro cut through a crater diameter. Projectile was fired vertically downward upon upper surface (at approximately the $80 \mathrm{~mm}$ mark). Measurements were made on the facing half of the sample corresponding to the left half of the figure. Cracks are highlighted by water-soluble saw coolant. The crack density near the impact site is great enough that individual cracks cannot be distinguished in this photograph.

The $\sim 1-\mathrm{cm}$ cubes from both samples were dried in an evacuated oven at $100^{\circ} \mathrm{C}$ until further weight loss over a 12 hour period was less than $10^{-4} \mathrm{~g}$, and seismic velocities were measured at $0.4 \mathrm{MHz}$. The $\mathrm{P}$ wave velocity $\mathrm{C}_{\mathrm{p}}$ of the unshocked gabbro and limestone were determined to be approximately $6.4 \pm 0.2$ and $3.9 \pm 0.1 \mathrm{~km} / \mathrm{s}$, respectively. We assume the $1-\mathrm{cm}^{3}$ samples are representative of the rock in bulk; that is, we believe no further crack damage was done upon sawing and in preparing the samples for ultrasonic measurements. The detailed velocity data are presented in Table 3. Although the velocity anisotropy of the unshocked samples was not determined, the differences in velocity in different directions is expected to be small relative to the velocity reductions seen in the data. This is confirmed by the directional velocity measurements far from the axis of impact, where the sound speed approaches the unshocked value, in Figures 9 and 11. The difference between the average velocity in the three principal directions is less than the scatter in velocities for each direction.

\section{RESULTS FOR AXISYMMETRIC EXPERIMENTS}

\section{Compressional Wave Velocity Measurements}

San Marcos Gabbro. Velocity measurements for aliquots of gabbro were measured in orthogonal directions as defined in Figure 7. Local seismic anisotropy was observed in the upper left part of the specimen, where major vertical fractures associated with the specimen edge can be observed (Figure 6). Such fractures are expected to reduce the crackperpendicular $(x)$ velocity much more than the crack-parallel $(z, y)$ velocities [Anderson et al., 1974], which is the observed result (Figure 8). The reduced $z$ velocities at the $1.5 \mathrm{~cm}$ depth are most likely due to the subhorizontal cracks associated with reflections from the free surface (Figures 6 and $7 a$ ).

Elsewhere, the anisotropy is less pronounced. Figure 8 illustrates the $\mathrm{P}$ wave velocity in the $x, y$, and $z$ directions at $2.5 \mathrm{~cm}$ depth within the sample. Within the central portion

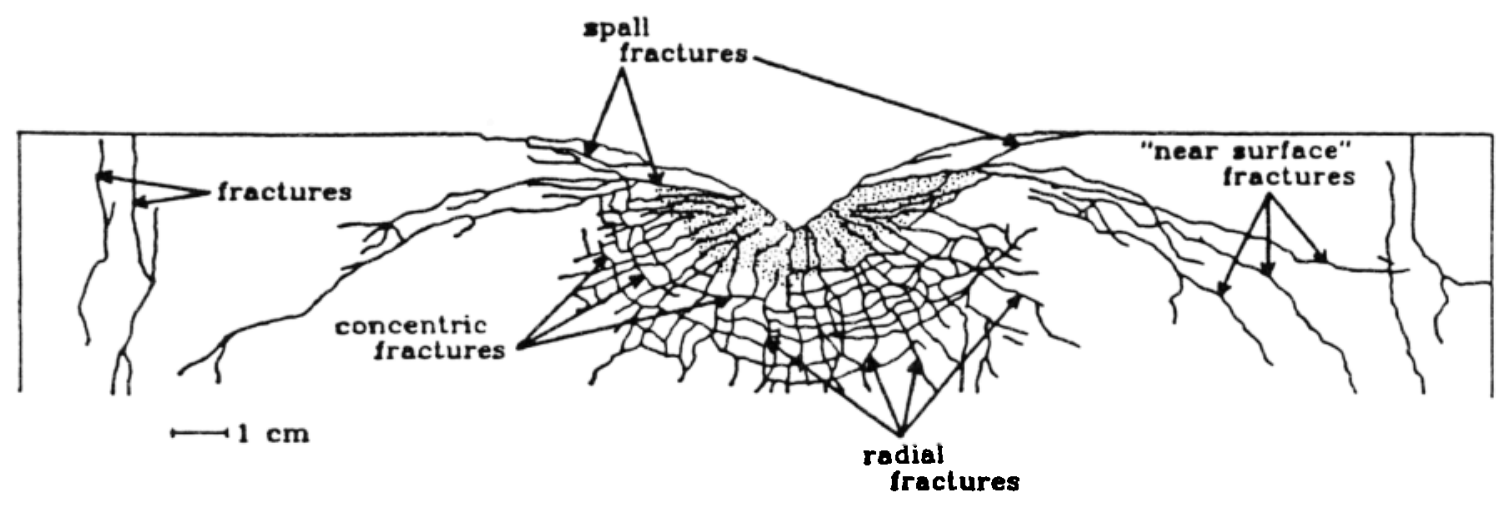

Fig. 6b. Cross section of the target from shot 840904 illustrating the classification of internal fractures. Note that all fractures have been drawn with the same line thickness despite actual variations in the target. The shaded arca immediately helow the crater indicates a highly fractured region [Polanskey and Ahrens, 1990]. 
TABLE 3a. Compressional Wave Velocity Beneath Impact Craters in Bedford Limestone

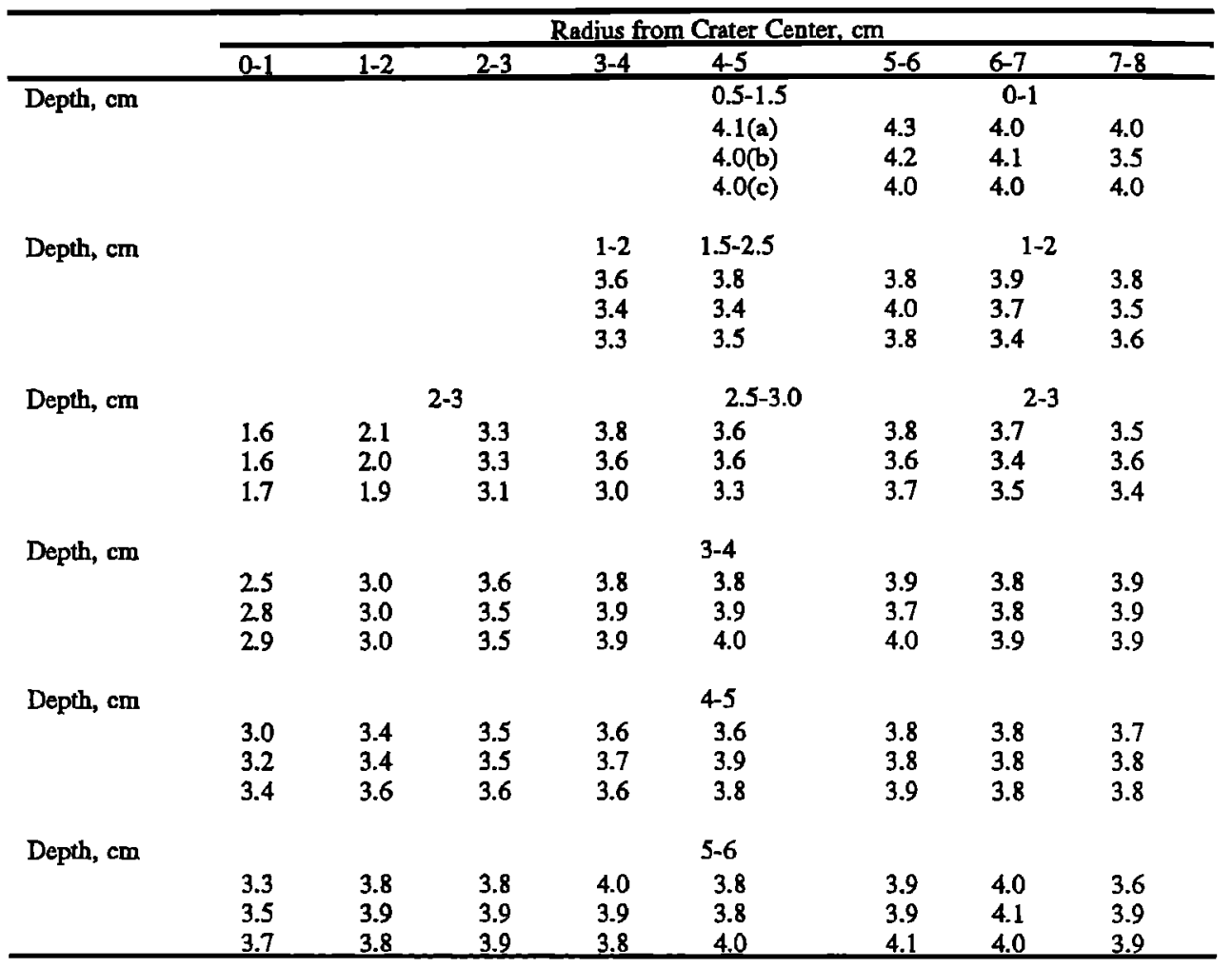

(a), (b), and (c) refer to compressional wave velocity along directions defined in Figure 5.

TABLE 3b. Compressional Wave Velocity Beneath Impact Craters in San Marcos Gabbro

\begin{tabular}{|c|c|c|c|c|c|c|c|c|c|c|}
\hline & \multicolumn{10}{|c|}{ Radius from Crater Center, cm } \\
\hline & $0-1$ & $1-2$ & $2-3$ & $3-4$ & $4-5$ & $5-6$ & $6-7$ & $7-8$ & $8-9$ & $9-10$ \\
\hline Depth, cm & & & & & & $0.5-1.5$ & & & $0-1$ & \\
\hline & & & & & & $\begin{array}{l}6.2(\mathrm{a}) \\
5.8(\mathrm{~b}) \\
6.0(\mathrm{c})\end{array}$ & $\begin{array}{l}6.8 \\
6.2 \\
6.4\end{array}$ & $\begin{array}{l}5.9 \\
6.4 \\
6.4\end{array}$ & $\begin{array}{l}4.7 \\
6.5 \\
6.0\end{array}$ & $\begin{array}{l}5.8 \\
6.6 \\
6.4\end{array}$ \\
\hline Depth, cm & & & & & & $1.5-20$ & & & $1-2$ & \\
\hline & & $\begin{array}{l}4.9 \\
4.1 \\
3.0\end{array}$ & $\begin{array}{l}5.7 \\
4.8 \\
4.9\end{array}$ & $\begin{array}{l}5.8 \\
6.0 \\
5.7\end{array}$ & $\begin{array}{l}6.0 \\
5.4 \\
5.9\end{array}$ & $\begin{array}{l}6.4 \\
5.8 \\
6.0\end{array}$ & $\begin{array}{l}6.3 \\
6.0 \\
6.1\end{array}$ & $\begin{array}{l}6.6 \\
6.1 \\
6.5\end{array}$ & $\begin{array}{l}4.8 \\
5.6 \\
6.1\end{array}$ & $\begin{array}{l}6.3 \\
5.7 \\
6.5\end{array}$ \\
\hline Depth, cm & & & & & & $2-3$ & & & & \\
\hline & $\begin{array}{l}4.5 \\
3.8 \\
4.2\end{array}$ & $\begin{array}{l}4.8 \\
4.5 \\
4.9\end{array}$ & $\begin{array}{l}5.7 \\
4.8 \\
5.0\end{array}$ & $\begin{array}{l}5.8 \\
5.5 \\
5.4\end{array}$ & $\begin{array}{l}6.1 \\
6.2 \\
6.2\end{array}$ & $\begin{array}{l}6.5 \\
6.2 \\
6.0\end{array}$ & $\begin{array}{l}6.7 \\
6.3 \\
6.5\end{array}$ & $\begin{array}{l}6.3 \\
6.3 \\
6.6\end{array}$ & $\begin{array}{l}4.8 \\
6.1 \\
6.6\end{array}$ & $\begin{array}{l}6.5 \\
6.4 \\
6.6\end{array}$ \\
\hline Depth, cm & & & & & & $3-4$ & & & & \\
\hline & $\begin{array}{l}4.8 \\
5.0 \\
4.9\end{array}$ & $\begin{array}{l}5.1 \\
5.0 \\
5.0\end{array}$ & $\begin{array}{l}5.4 \\
5.7 \\
5.3\end{array}$ & $\begin{array}{l}5.9 \\
6.2 \\
5.8\end{array}$ & $\begin{array}{l}6.2 \\
6.1 \\
5.9\end{array}$ & $\begin{array}{l}6.5 \\
6.6 \\
6.3\end{array}$ & $\begin{array}{l}6.5 \\
6.5 \\
6.3\end{array}$ & $\begin{array}{l}6.1 \\
6.2 \\
6.4\end{array}$ & $\begin{array}{l}6.0 \\
6.1 \\
6.3\end{array}$ & $\begin{array}{l}5.9 \\
6.2 \\
6.6\end{array}$ \\
\hline Depth, cm & & & & & & $1-5$ & & & & \\
\hline & $\begin{array}{l}5.8 \\
5.5 \\
5.4 \\
\end{array}$ & $\begin{array}{l}5.6 \\
6.0 \\
5.6 \\
\end{array}$ & $\begin{array}{l}5.8 \\
6.0 \\
5.5 \\
\end{array}$ & $\begin{array}{l}5.7 \\
6.3 \\
5.7 \\
\end{array}$ & $\begin{array}{l}6.1 \\
6.2 \\
5.9 \\
\end{array}$ & $\begin{array}{l}6.1 \\
6.6 \\
6.3 \\
\end{array}$ & $\begin{array}{l}6.2 \\
6.4 \\
6.7\end{array}$ & $\begin{array}{l}6.0 \\
6.3 \\
6.2 \\
\end{array}$ & $\begin{array}{l}5.9 \\
6.4 \\
6.2 \\
\end{array}$ & $\begin{array}{l}6.1 \\
6.5 \\
6.7 \\
\end{array}$ \\
\hline
\end{tabular}

See Table $3 a$ footnote. 
$\mathrm{Pz}$
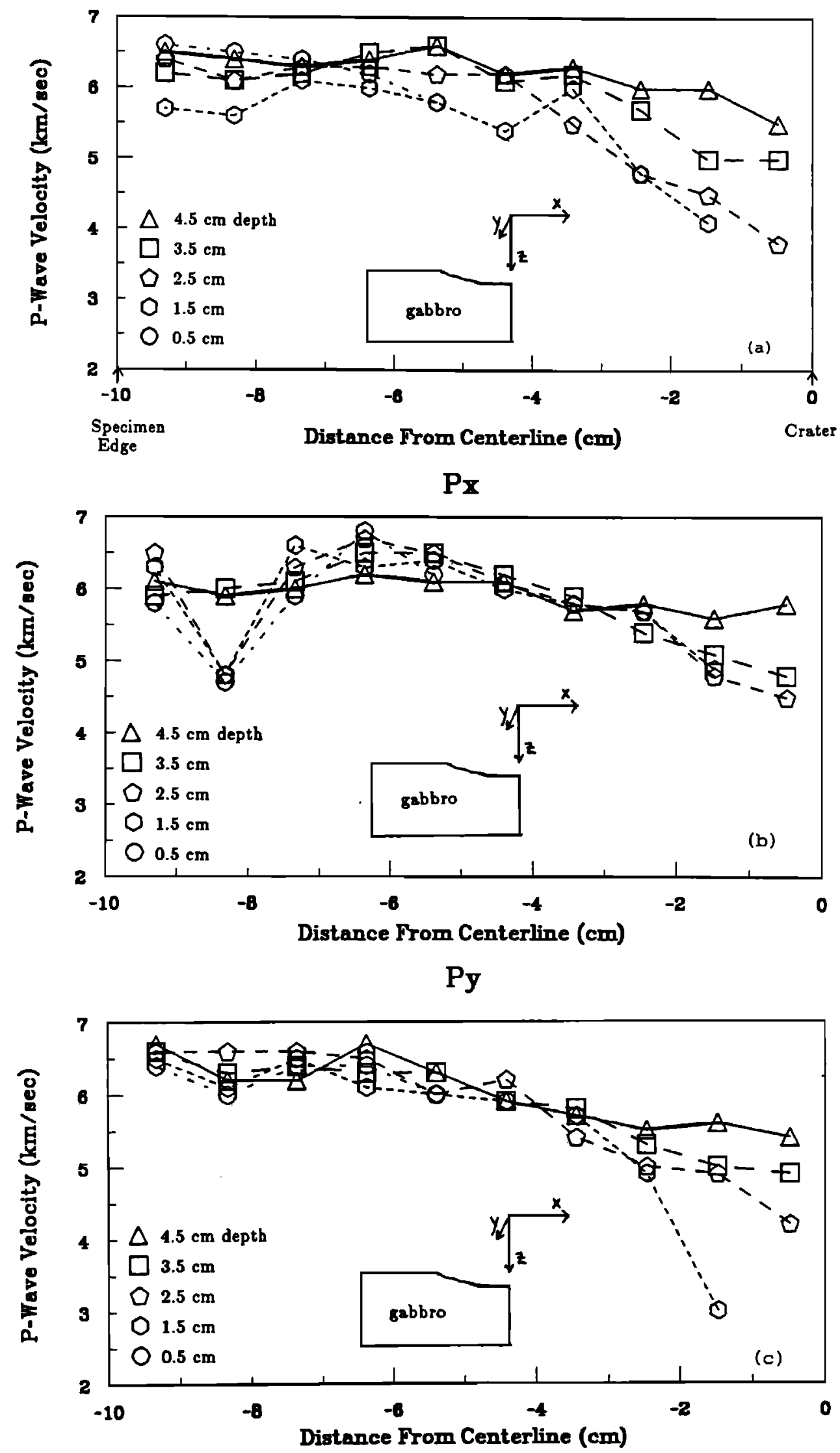

Fig. 7. $P$ wave velocities for gabbro as a function of distance from the $z$ axis (projectile path), at indicated depths within the sample. Sample velocities farthest below the impact site are generally the highest. (a) $\mathrm{Pz}$, velocity in $\mathrm{z}$ direction; (b) $\mathrm{Px}$, velocity in $\mathrm{x}$ direction; (c) Py, velocity in y direction (see sketch). 


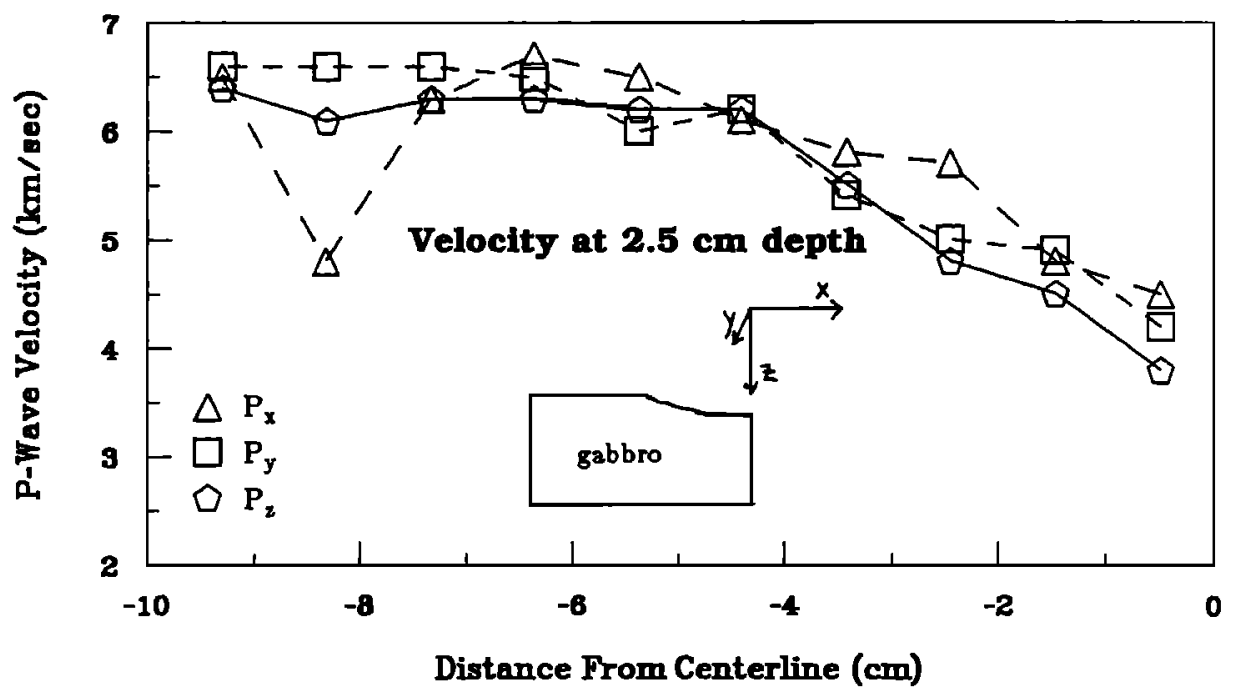

Fig. 8. $P$ wave velocities for gabbro in $x, y$, and $z$ directions at $2.5 \mathrm{~cm}$ depth below the surface. The pronounced anisotropy near the sample edge is due to the oriented macroscopic cracks visible in Figure 6 . It also appears that the $\mathrm{z}$ direction is slowest of the three beneath the crater, but reaches its far-field velocity at lesser distances than the $\mathrm{x}$ and $\mathrm{y}$ directions.

of the crater the vertical ( $z$ ) velocity is slightly but consistently less than both horizontal $(x, y)$ velocities. This is consistent with the large subhorizontal cracks somewhat concentric with the crater floor (Figure 6). In addition, from Figures 7 and 8 it appears that with the exception of the sample located at a depth of $1.5 \mathrm{~cm}$, the vertical ( $z$ ) P wave velocity appranches unshocked values at lesser radial distances than do the horizontal $(x, y)$ velocities (approximately $4.5 \mathrm{~cm}$ as opposed to $6.5 \mathrm{~cm}$ ). The $1.5-\mathrm{cm}$ depth layer includes the large sub-horizontal cracks outside the crater region in Figure 6.

Figure 9 shows all the velocity measurements for gabbro versus radial distance from the assumed effective center (located at $1 / 2$ the crater depth) of the approximately hemispherical stress wave emanating from the impact. The seismic velocity increases smoothly to its unshocked value at a radial distance of approximately one crater radius. The average velocity in the vicinity of the crater floor is approximately 0.65 times the unshocked velocity.
Bedford Limestone. The velocity measurements on limestone (Figures 10 and 11) resemble those made on the gabbro. The seismic velocity, occurring just beneath the crater floor, is reduced to values slightly less than half the unshocked value. The maximum velocity reduction is slightly greater for the limestone ( 0.59 times the unshocked value) than for the gabbro ( 0.53 times the unshocked value). These velocity reductions are some $50 \%$ greater than those observed in the one-dimensional experiments described previously in this paper. Although the loading history of a given zone of rock differs between the uniaxial and cratering experiments, the greater velocity reductions are probably the result of the greater damage which can be inflicted on rock which is internal to a massive block on account of the intrinsic inertial confinement of three-dimensional geometry. Seismic anisotropy within the limestone, if present, is much less than within the gabbro. This is particularly evident nearest the crater center, where the scatter in velocity for the limestone (Figure 11) is strikingly less than for the gabbro

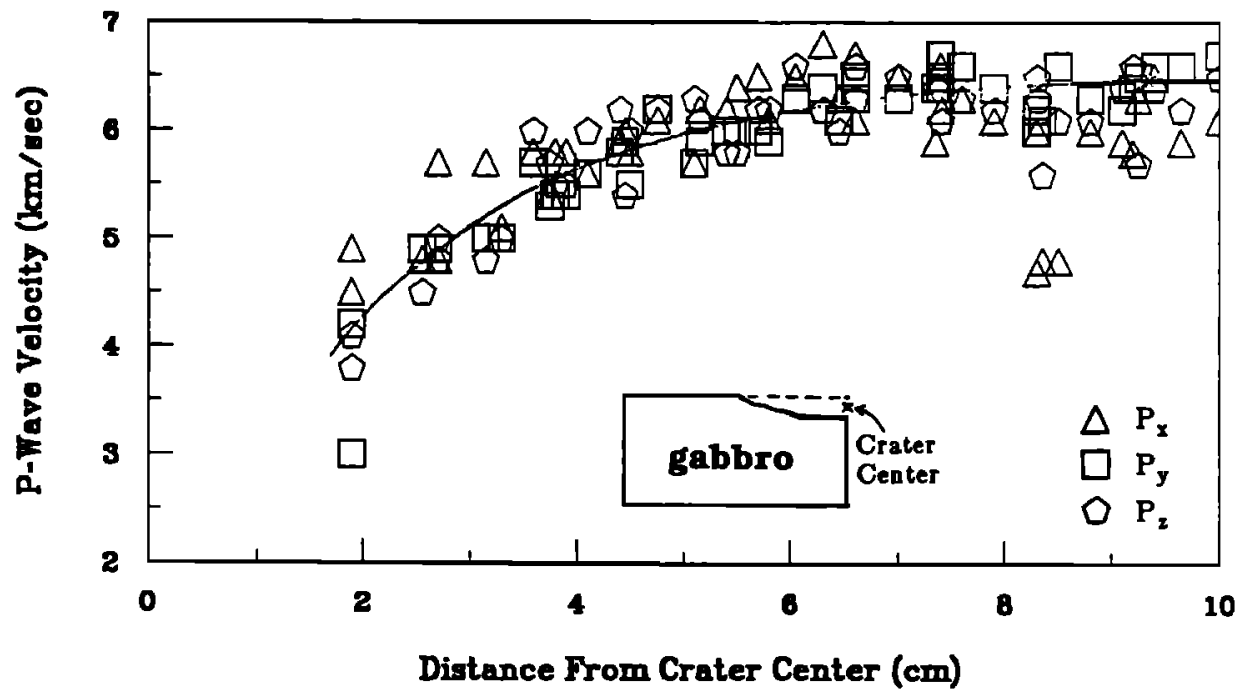

Fig. 9. Plot of all velocity measurements for gabbro as a function of distance from the crater center. Curve is eyeball fit to data. $\mathrm{Px}, \mathrm{Py}$, and $\mathrm{Pz}$ refer to wave propagation along the direction as defined in Figure. 

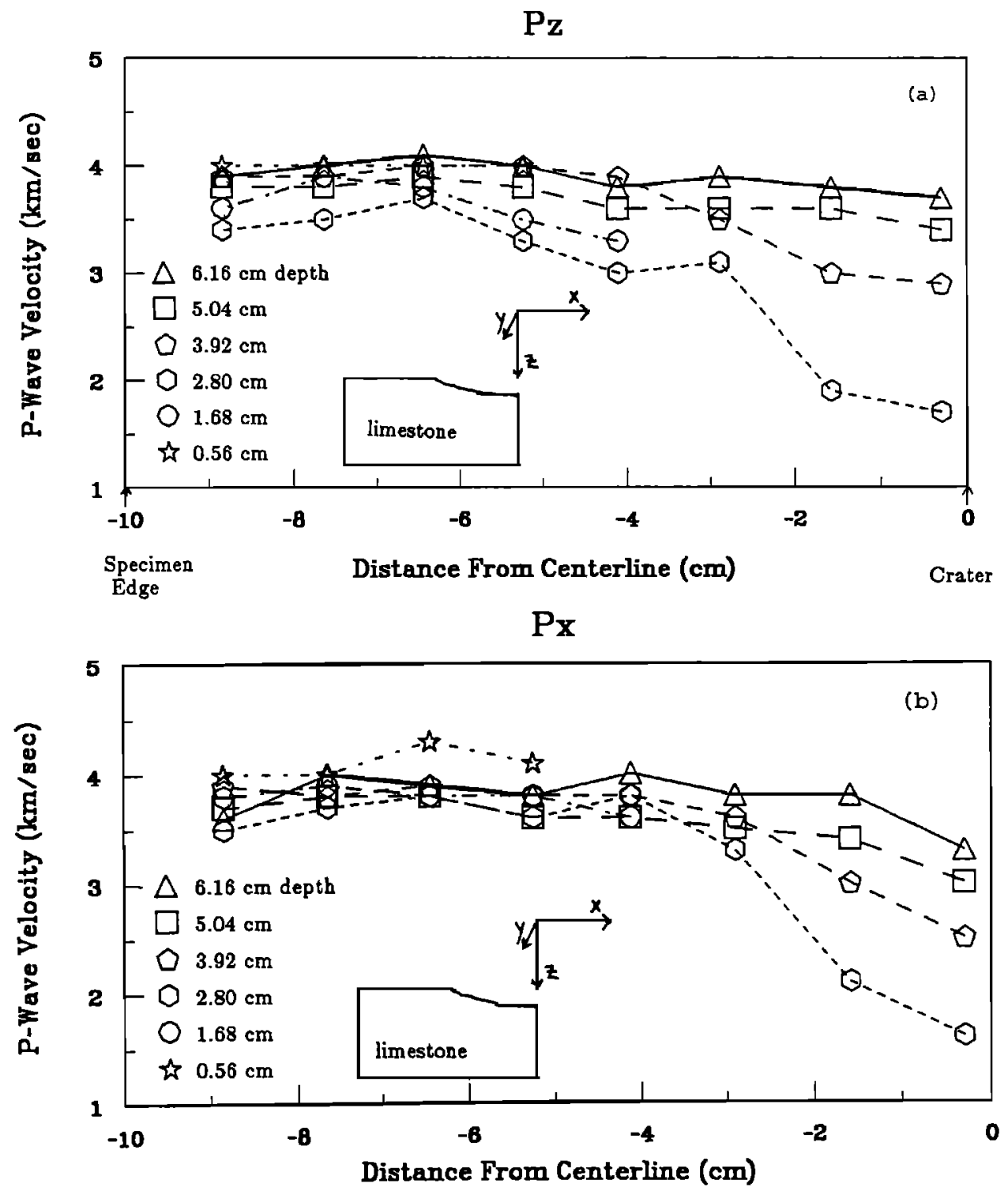

Py

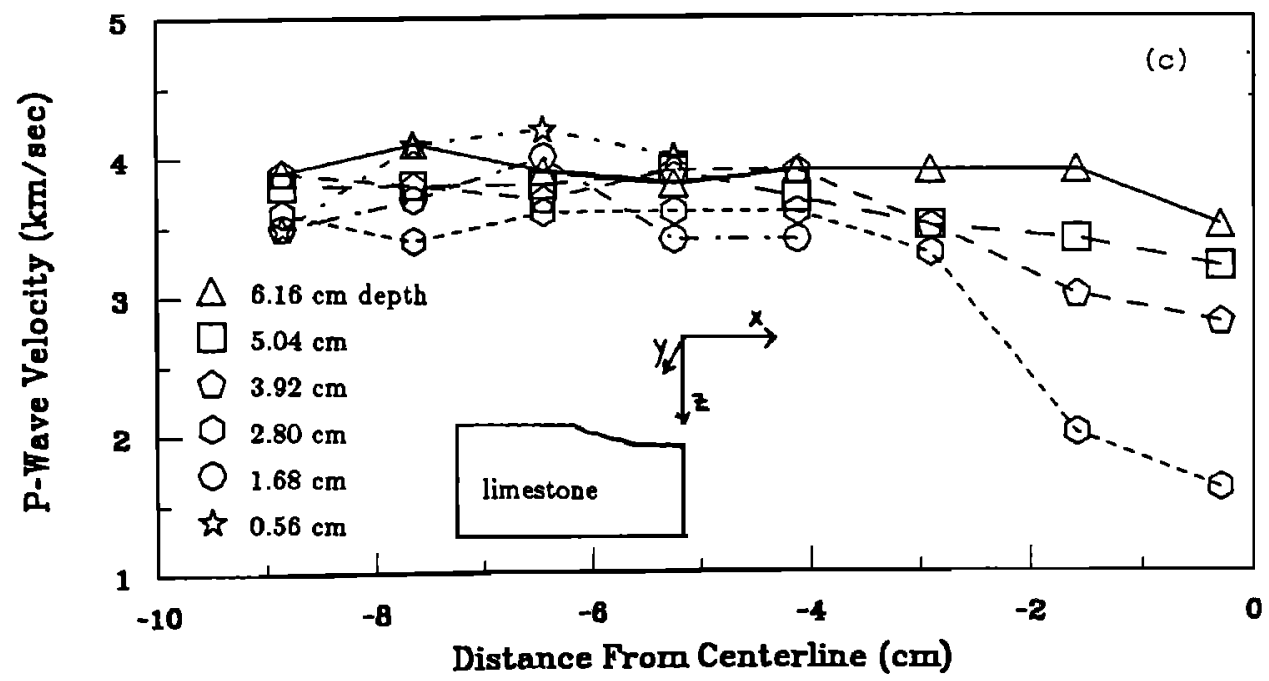

Fig. 10. P wave velocities for Bedford limestone as a function of distance from the $\mathbf{z}$ axis (projectile path), at indicated depths within the sample. Sample velocities furthest below the impact site are generally the highest. (a) Px, velocity in $z$ direction; $(b)$ $\mathrm{PX}_{\mathrm{x}}$ velocity in $\mathrm{x}$ direction; (c) Py, velocity in y direction (soe sketch). 


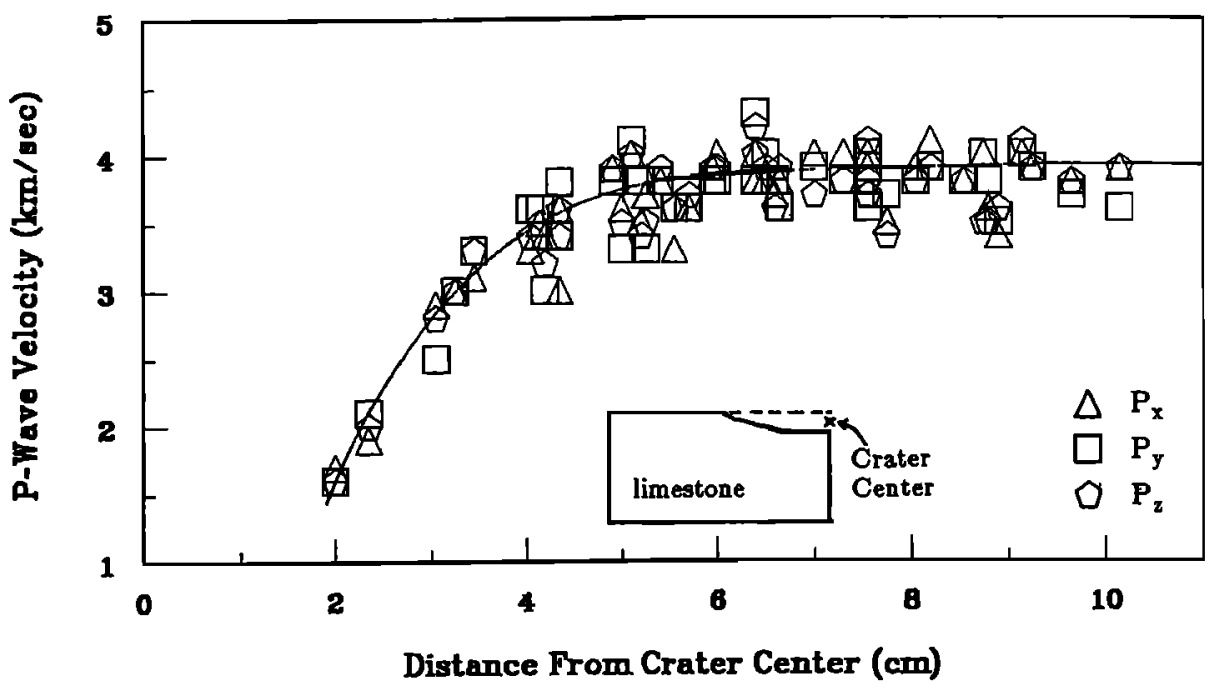

Fig. 11. Plot of all velocity measurements for Bedford limestone as a function of distance from the crater center. Peak stress levels in rock vary from $900 \mathrm{MPa}$ at $2 \mathrm{~cm}$ to $200 \mathrm{MPa}$ at $5 \mathrm{~cm}$.

(Figure 9). The compressional wave velocities increase relatively smoothly with distance from the crater center (Figure 11). The average of the velocity reductions at distances less than approximately one crater radius is significantly greater within the limestone than within the gabbro. The seismic velocity approaches its unshocked value at a slightly lesser distance, relative to the crater radius, in the limestone than in the gaobro.

\section{Correlation with Crack Density}

Comparison of Figure 6 with Figures 9 and 11 indicates that the zones of greatest velocity reduction correspond closely to the zones of greatest crack concentration.

Microscopic observation of the 1-cm cubes of gabbro at $25 x$ indicates cracks ranging from grain boundary cracks and cleavage cracks internal to plagioclase and amphibole (0.1-1 $\mathrm{mm}$ ) to cracks which apparently traverse the entire cube.
Cleavage cracks and grain-crossing cracks are restricted largely to highly shocked low-velocity samples near the impact. Both crack density and maximum crack length increase as seismic velocity decreases. Thus samples with relatively high velocities far from the impact have about 1 crack of average length $0.5 \mathrm{~mm}$ per $\mathrm{mm}$ of traverse, while samples close to the impact bave as many as 2.3 cracks of average length $1.2 \mathrm{~mm}$ per $\mathrm{mm}$ of traverse.

Existing theories relating seismic velocity reduction to crack density assume either that the cracks are randomly oriented [e.g., O'Connell and Budiansky, 1974], or uniformly aligned [e.g., Anderson et al., 1974]. The cracks within the cubes cut from the shocked gabbro have preferred but nonuniform orientations and are therefore an intermediate case to those modeled theoretically. The crack density parameter in these studies is $\varepsilon=N\left\langle a^{3}\right\rangle$, where $N$ is the number of cracks per unit volume and $\left\langle\mathrm{a}^{3}\right\rangle$ is the average of the cube of the characteristic linear dimension (half length) of the crack

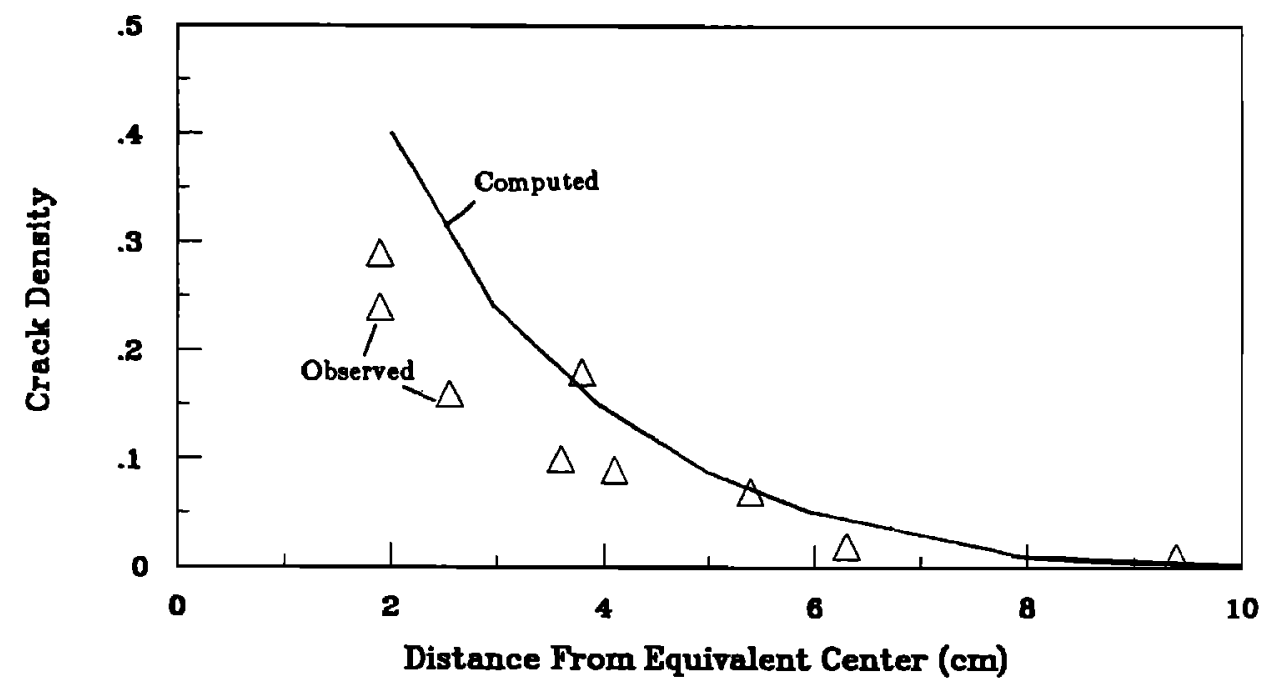

Fig. 12. Plot of maximum observational estimate of $\varepsilon$ for each gabbro sample measured (triangles), as a function of distance from the crater center. Also shown is the computed plot of $\varepsilon$ versus distance, using the theory of $O^{\prime} C o n n e l l$ and Budiansky [1974] and the fit to the velocity data from Figure 9 (solid line). 
[O'Connell and Budiansky, 1974, equation (4)]. Because of the $\mathrm{a}^{3}$ term the influence on velocity is heavily weighted toward the largest cracks present. O'Connell and Budiansky [1974] relate $\varepsilon$ to the observed crack trace density statistically by

$$
\varepsilon=\frac{3}{4 \pi} M<l^{2}>,
$$

where $M$ is the number of line segments per unit area and $I$ is the observed segment length. Optical estimates of $\varepsilon$ were made on nine cubes at various distances from the crater center. Independent estimates were obtained for each of the $x, y$, and $z$ directions, based on the number and lengths of cracks with length greater than $0.4 \mathrm{~mm}$ crossed by oriented traverses. Estimates of $\varepsilon$ ranged from 0.01 near the specimen edge to 0.28 just beneath the crater. The range of directional values of $\varepsilon$ within a single sample were typically considerably greater than the observed range of seismic velocity measurements for the sample and the largest value of $\varepsilon$ is plotted in Figure 12 .

Using the $O^{\prime}$ Connell and Budiansky (random orientation) theory, $\varepsilon$ is computed from

$$
\begin{gathered}
\frac{\overline{\mathrm{K}}}{\mathrm{K}}=1-\frac{16}{9}\left(\frac{1-\bar{v}^{2}}{1-2 \bar{v}}\right) E \\
\frac{\bar{v}}{v}=1-\frac{16}{9} \varepsilon \\
\frac{\overline{C_{\mathrm{p}}}}{\mathrm{C}_{\mathrm{p}}}=\left(\frac{(1-\bar{v})(1+v)}{(1+\bar{v})(1-v)} \frac{\overline{\mathrm{K}}}{\mathrm{K}}\right)^{1 / 2}
\end{gathered}
$$

where $\mathrm{K}$ is bulk modulus, $v$ is Poisson's ratio, and bars denote effective values appropriate for the cracked body. The values of $\varepsilon$ that would reproduce the fit to the velocity data in Figure 9 are shown in Figure 12, together with the values determined optically. An initial crack density $\varepsilon$ of 0.0 (for practical purposes equal to the lowest observed value of 0.01 ) was assumed. The computed values of $\varepsilon$ are up to a few tens of percent greater than the observed values. The computed value of $\varepsilon$ producing the maximum $P$ wave velocity reduction of $50 \%$ is $\mathbf{0 . 4}$, as opposed to the observed value of 0.28 . This discrepancy could be due in part to the neglect of cracks less than $0.4 \mathrm{~mm}$ in length. The theory of $O^{\prime}$ Connell and Budiansky [1974], which assumes random crack orientation, cannot be used in this simplified fashion to describe the directional properties of the velocity measurements in detail. Further microscope observation, shear wave velocity measurements, and consideration of aligned-crack models are necessary to determine if refinements of the theoretical models relating crack density to modulus reduction in shocked rock are required.

Observation of the crack density in the limestone at a magnification of $50 \mathrm{X}$ indicates that in the closest region, about $2 \mathrm{~cm}$ distant, nearly all the grains are severely fractured and shattered. A short distance further about half the grains are fractured, with from 1 to about 10 cracks each. By about $3 \mathrm{~cm}$ distant, only about $5 \%$ of the grains contain visible fractures, although the velocity reduction is still pronounced. These observations indicate that the initial stage of inelastic failure involves fracture along grain boundaries, which could explain the apparent lack of anisotropy of the velocity measurements.

\section{APPLICATION OF LINEAR ELASTIC FRACTURE MECHANICS TO FRACTURE DAMAGE IN THREE DIMENSIONS}

\section{Mechanism of Shock Damage}

Detailed studies of crack patterns within impact craters in rock [e.g. Polanskey and Ahrens, 1990], indicate that some three families of cracks are produced upon impact onto a half space of brittle media such as rock. These three crack families are (1) radial, (2) concentric, and (3) spall fractures (Figure 13). There exist two families of radial fracture (spoke and conical) which are sketched in Figure 14. Field's [1971] study suggests that radial crack formation initiates immediately behind the outgoing stress wave, whereas the concentric cracks are initiated at later times and appear to be related to the tensile phase of the stress pulse, associated with sudden release of the impulsive load applied at the surface [Selberg, 1952; Shibıya and Nakahara, 1968]. The spall fractures parallel to the impact surface are believed to result from the interaction of the compressive stress pulse with the free surface [Melosh, 1984; Swain and Hagern, 1980], as are the vertical cracks near the edges of the sample. Shibuya and Nakahara [1968, Figures 5 and 6] demonstrate that the hoop stresses $\sigma_{\theta \theta}$ and $\sigma_{\phi \varphi}$, which are responsible for the radial fractures, reach their peak tensile value behind the outgoing compressive wave front, immediately prior to the arrival of the shear wave. In the following we assume that the bulk of the damage is produced by both types of radial cracks, whose formation is more straightforwardly relatable to calculated stress wave profiles.

Such radial cracks which grow are perpendicular to the direction of peak tension, and thus normal to the quasispherical compressive wave front. We first test the hypothesis that these cracks begin to grow at the time $t_{c}$ given by (5). At a time $t>t_{c}$ after the onset of a tensile stress pulse, cracks of initial length $\ell_{0}$ will increase in length by $\Delta \ell=C_{s}\left(t-t_{c}\right)$, assuming they grow at the shear wave velocity. Substituting (5) for $t_{c}$, we have

$$
\Delta=C_{s} t-\frac{\pi}{4} \frac{K_{c}^{2}}{\sigma^{2}}
$$

The relation between the crack damage parameter $\varepsilon$ of O'Connell and Budiansky [1974] and the cracked compressional wave velocity $C_{p}$ can be approximated by

$$
1-\frac{C_{p}}{C_{p o}}=\alpha_{p}\left(\varepsilon-\varepsilon_{0}\right)
$$

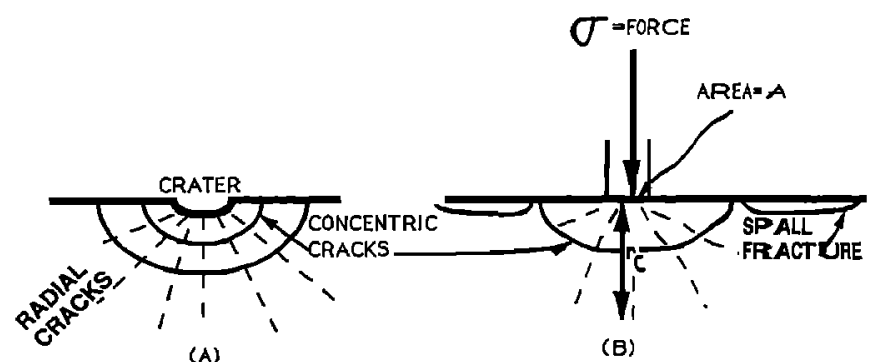

Fig- 13. Diagrammatic cross-section showing three crack families, radial, concentric, and spall fractures: (a) geometric definition and (B) definition of parameters of Anstis at aL [1981] radial spoke ficacture model. 


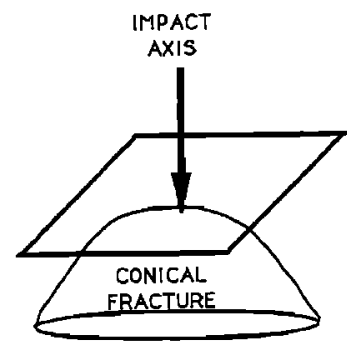

(A)

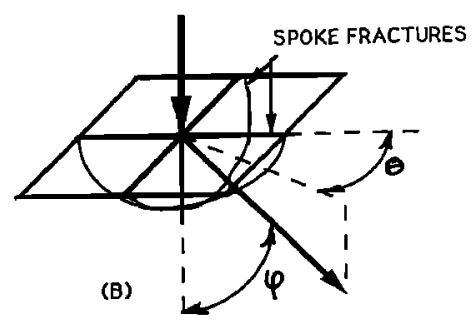

Fig. 14. Two subclasses of radial fractures from impact: (a) conical fracture and $(b)$ spoke fracture.

where $\alpha_{\mathrm{p}}$ is a constant given approximately by 1.3 over the range $0 \leq \varepsilon \leq 0.4$ [see O'Connell and Budiansky, 1974, Figure 6]. Since

$$
\varepsilon / \varepsilon_{0}=\left\langle\ell^{3}\right\rangle \mid\left\langle\ell_{0}^{3}\right\rangle
$$

assuming all existing cracks are of similar length and grow by $\Delta \ell$, we find upon linearizing (equation (12)), and substituting into (11), that

$$
1-\frac{C_{p}}{C_{p o}} \equiv \alpha_{p} \varepsilon_{0}\left[\left(1+3 \Delta \ell / \ell_{0}\right)-1\right]
$$

Upon substituting (10) into (13), we obtain

$$
1-\left(C_{p} / C_{p o}\right)=3 \alpha_{p} E_{o}\left\{C_{s} t-\pi K_{c}^{2} /\left(4 \sigma^{2}\right)\right] / \ell_{0}
$$

The first term in braces in (14) predicts the behavior of velocity deficit with time, at constant tensile stress, whereas the second term yields a prediction of how velocity deficit varies with tensile stress amplitude, which we can relate to radial distance.

We can employ the results of the one-dimensional experiments to compare with the predictions of the " $\mathrm{C}_{\mathrm{s}} \mathrm{t}$ " term. For example, we note that the velocity deficit is predicted to be linear with time, at constant tensile stress. Using Figure 2, we note that for 0.5 - and 1.3- $\mu$ s duration tensile stress pulses with amplitudes of $70 \mathrm{MPa}$, velocity deficits 3 and $30 \%$ are observed, respectively. The first term in braces would predict a $8 \%$ velocity deficit at $1.3 \mu$ from the $0.5 \mu \mathrm{s}$ value, whereas a $30 \%$ deficit is observed. Thus, the first term underestimates the effect of time duration of applied tensile stress. The second term overestimates a dependence of velocity deficit on tensile stress $\left(\propto \sigma^{-2}\right)$, whereas a dependence $(\propto \sigma)$ is observed.

\section{Parameterization of Impact Damage}

In this section we relate the damage parameter $D$, observed as a function of distance in the axi-symmetric experiments, to computations of $D$ as a function of tensile stress magnitude and duration. Because we find that damage as detected via both longitudinal $D_{p}$ and shear $D_{s}$ wave velocity deficits are indistinguishable in the present experiments (Figures 2 and 4), we simply employ the variable $D$. An expression for $\mathrm{dD} / \mathrm{dt}$ can be based on theories of the nucleation and growth of cracks which have an initial Weibull distribution [Grady, 1980; Grady and Kipp, 1987]. A Weibull distribution specifies that the number of cracks per unit volume $n$ activated at or below a tensile strain $\boldsymbol{\Sigma}$ are given by

$$
\mathbf{n}=\mathbf{k} \mathbf{\Sigma}^{\mathbf{m}}
$$

where $\mathbf{k}$ and $\mathrm{m}$ are empirical constants. Grady and Kipp [1987] find

$$
\begin{gathered}
\frac{d D}{d t}=(36 \pi)^{1 / 3}\left[k\left(\frac{\sigma}{M(1-D)}\right)^{m}\right]^{1 / 3} \\
C_{g} D^{2 / 3}(1-D)^{(1-m / 3)}
\end{gathered}
$$

respectively. Here $M$ is the modulus of the wave (either longitudinal or shear), and $\mathrm{C}_{\mathrm{g}}$ is the crack propagation velocity which we assume here is given by $C_{s}$.

Upon separating variables,

$$
\begin{gathered}
{\frac{(1-D)}{D^{2 / 3}}}^{(m / 3)-1} \mathrm{dD}=(36 \pi)^{1 / 3} \\
{\left[k(\sigma / M)^{m}\right]^{1 / 3} C_{g} d t}
\end{gathered}
$$

Approximating the left hand side of (17) by $[1-[(\mathrm{m} / 3)$ 1]D) $/ D^{2 / 3}$ yields, upon also dropping terms of order $D^{4 / 3}$ relative to terms of order $D^{1 / 3}$ :

$$
\mathrm{D} \cong \frac{4}{3} \pi k(\sigma / M)^{m} C_{g} t^{3}
$$

We shall relate (18) and the experimental results to observations of damage from impact-induced quasihemispherical shock waves in gabbro and limestone. The maximum damage $\mathbf{D}$ for a constant duration of tensile stress application, as measured by either $P$ or $S$ wave velocity deficits, can empirically ( e.g., Figure 4 ) be described by a relation of the form

$$
\mathrm{D}=\mathrm{A}_{\mathbf{n}} \boldsymbol{\sigma}^{\mathrm{m}} \quad, \quad \mathrm{n}=0.5 \text { and } 1.3
$$

where for the solid curves shown in Figure $4, \mathrm{~m}=3$ and $A_{0.5}=2 \times 10^{-6} \mathrm{MPa}^{-3}$ and $\mathrm{A}_{1.3}=1.37 \times 10^{-7} \mathrm{MPa}^{-3}$, respectively, for the 0.5 - and $1.3-\mu$ s duration experiments. The parameters of the solid curves of Figure 4 are constrained by the data. For example, the dashed curve through the 1.3$\mu$ s data has the parameters, $\mathrm{A}_{1.3}=2 \times 10^{-6} \mathrm{MPa}^{-2.5}$ and $\mathrm{m}=2.5$.

Thus, from Figure 4, at constant $t$, we obtain $m=3$. Moreover, we see that $m=2.5$ does not fit the $1.3-\mu \mathrm{s}$ duration data. The solid curve fits shown in Figure 4 are a compromise. Here, $m=3$ is an upper bound to the 1.3- $\mu \mathrm{s}$ data, whereas it is slightly lower than what would give an optimum fit to the $0.5-\mu \mathrm{s}$ data. This compares to $m=9.1$ obtained by Lange et al. [1984] for impact spall of the present San Marcos gabbro, and $m=8$ obtained by Grady and Kipp [1987] in fragmentation studies on oil shale. The peak dynamic compressional (and the following tensional) stress from an impact on a half-space is expected to approach a $\mathrm{r}^{-2}$ dependence [Melosh, 1989]. However, very close to the impact the stress wave decay is less rapid [Ahrens and $O^{\prime}$ Keefe, 1977]. We therefore assume that in the regime of interest $\sigma \propto r^{-1.5}$. Moreover, numerical calculations of Shibuya and Nakahara [1968] found the duration of the tensile hoop stress associated with the longitudinal wave $t$ was proportional to radius, i.e., $t \propto x$. 


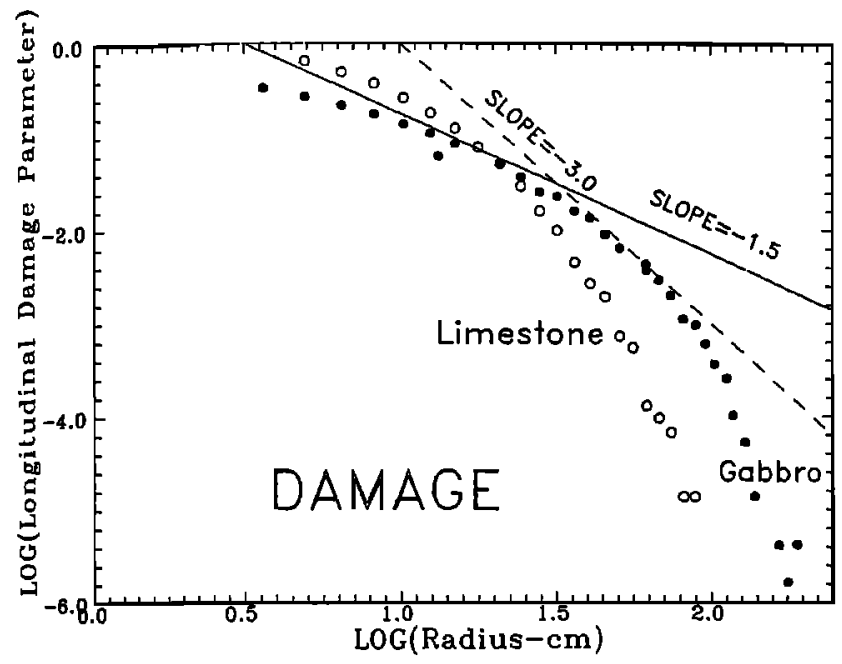

Fig. 15. Log, damage (longitudinal wave) parameter versus $\log$, radius in centimeters, for impact experiments on blocks of Bedford limestone and San Marcos gabbro.

Therefore, we predict for the limestone from (18), for the damage associated with the outgoing longitudinal wave that

$$
D \propto\left(r^{-1.5}\right)^{\mathrm{m}} r^{3}
$$

or

$$
D \propto r^{-1.5}
$$

In Figure 15, it can be seen that this predicted decay of D agrees well with the initial slope of limestone data. Undoubtedly, other dynamic stresses (in addition to $\sigma_{\theta \theta}$ and $\left.\sigma_{\phi \varphi}\right)$ affect the crack damage parameter. However, radial cracking appears to result from the tensile stress associated with the elastic longitudinal wave and the decay of this stress is well described. We note that if we assume a $\sigma \propto \mathrm{I}^{-2}$ dependence, rather than $r^{-1.5}$, equation (20) then predicts that $D \propto \mathrm{r}^{-3}$. Notably, this more rapid stress decay fits the data of Figure 15 further from impact point in the more nearly elastic regime.

We note that if the $m=9.1$ value for gabbro is employed in (20), then a dependence of $D \propto r^{-10.5}$ is predicted. This is a much stronger (and less credible) dependence on $\mathbf{r}$ than obtained using $m=3$. It may be that values of " $m$ " from fragmentation experiments such as those of Langeet al. [1984] simply do not apply.

Finally, the extent of radial cracking beneath the crater is also approximately described by cracking in the "spoke" mode as discussed in the appendix.

\section{CONCLUSIONS}

Samples of Bedford limestone were subjected to planar impacts in order to produce tensile failure under conditions of nearly one-dimensional strain to obtain the fracture toughness under dynamic loading conditions. Modern theories of the damage mechanics of brittle solids are able to relate the fracture toughness of rock (measured under tensile stress) to compressive failure [e.g., Ashby and Sammis, 1990; Isida and Nemat-Nasser, 1987]. Impact velocities were chosen to cover a range of stresses at and below those required to produce complete spalling, and the ultrasonic velocities of the recovered samples were measured to assess the degree of microcracking. The experiments were of 0.5 and 1.3- $\mu$ s duration. Major conclusions are as follows:
1. The onset of microcracking occurs at lower stresses for the longer-duration experiments; approximately $35 \mathrm{MPa}$ as opposed to $60 \mathrm{MPa}$. Complete spalling also occurs at lower stresses for the longer duration experiments; approximately $60 \mathrm{MPa}$ as opposed to $140 \mathrm{MPa}$.

2. Estimates of the rock fracture toughness based on the stress at the onset of microcracking yield consistent results: $2.4 \mathrm{MPa} \mathrm{m}^{1 / 2}$ for the $1.3-\mu$ s experiments and $2.5 \mathrm{MPa} \mathrm{m}^{1 / 2}$ for the $0.5-\mu \mathrm{s}$ duration experiments. These values are somewhat higher than the quasi-static values determined for porous limestone, which range from 0.8 to $1.2 \mathrm{MPa} \mathrm{m}^{1 / 2}$.

3. Estimates of the initial flaw size activated during failure are $6.8 \mathrm{~mm}$ for the $1.2-\mu \mathrm{s}$ duration experiments and $2.8 \mathrm{~mm}$ for the $0.5-\mu \mathrm{s}$ duration experiments. In comparison, the largest grains in Bedford limestone are approximately 2 $\mathrm{mm}$ in length. One possible explanation for the relatively large computed size of the initial flaws is that in porous rock several closely spaced flaws must interact to produce crack growth at relatively low stresses. This could be an important mechanism in controlling dynamic failure in porous material.

4. Three-dimensional laboratory impact experiments were performed on crystalline (San Marcos gabbro) and porous (Bedford limestone) rocks. The targets were approximately $20 \mathrm{~cm}$ on a side and the resulting craters were approximately $5 \mathrm{~cm}$ in radius and $1 \mathrm{~cm}$ deep. The seismic velocities of oriented $1-\mathrm{cm}$ cubes were measured from the sectioned targets and related to induced crack densities via the theory of $O^{\prime}$ Connell and Budiansky [1974] and optical microscope observations. We compare the results from the porous and crystalline tests: (1) In both cases the impacts resulted in a seismic velocity (elastic modulus) reduction within the target that decayed essentially monotonically with distance from the impact site. (2) The average velocity reduction within the most heavily shocked region was greater within the limestone (approximately 0.4 times the unshocked value) than the gabbro (approximately 0.65 times the unshocked value), despite the fact that the peak pressure was greater within the gabbro. The seismic velocity approaches its unshocked value at lesser radial distance within the shocked limestone than within the shocked gabbro, suggesting greater attenuation within the porous limestone.

5. The radius of significant fracture damage beneath the impact craters was found to be describable by the quasi-static theoretical relation of radial cracking to fracture toughness of Anstis et al. [1981] (see the appendix). Using measured values of fracture toughness of 2.45 and $5.23 \mathrm{MPa} \mathrm{m}^{1 / 2}$ for Bedford limestone and San Marcos gabbro, inferred impact stresses agreed to within $-50 \%$ of that inferred from conventional shock impedance calculations.

6. If nucleation and growth of cracks from an initial Weibull distribution is assumed, the radial dependence of the crack damage parameter in Bedford limestone is predicted to be $D \propto r^{-1.5}$ on the basis of the time and stress dependence of the Grady and Kipp [1987] damage model, and the present one-dimensional tensile stress experiments. This is in approximate agreement with the observed variation of $D$ in the three-dimensional experiments on limestone.

\section{APPENDIX: EXTENT OF FRACTURE FROM QUASI-STATIC CONSIDERATIONS}

The extent of fracture from impacts into solid brittle media can be related to the fracture toughness of the target. Anstis et al. [1981] developed a semiempirical theory for which it was demonstrated that the radius of the radial 
(spoke) fracture, $I_{c}$ (Figure 14b) beneath quasi-static indention into a brittle medium half-space is related to the mode I fracture toughness via

$$
\mathbf{K}_{c}=\sigma A /\left(\beta_{o} r_{c}^{3 / 2}\right)
$$

where $\sigma$ and $A$ are the compressive force and area of an indentor acting on a half-space and $\beta_{0}$ is an empirical (dimensionless) constant. Using indention data assembled by Anstis et al. for some 13 ceramics and glasses, we find that $\beta_{0}=16.2 \pm 5.1$. We now use the measured values of $r_{c}$, $A$, and $K_{c}$ in equation (10) to calculate the impact stress, $\sigma$, and compare it to the impact stresses calculated from the conventional shock wave equation of state [Ahrens, 1986]. We have already obtained values of $r_{c}$ and $A$ from knowledge of the distance that the sound speed is degraded in the target and the projectile diameter given above. We note that from Figures 9 and $11, r_{c} \equiv 5 \mathrm{~cm}$ for both impact into gabbro and limestone. We have determined $\mathbf{K}_{c}$ for Bedford limestone as $2.45 \mathrm{MPa} \mathrm{m} \mathrm{m}^{1 / 2}$. For San Marcos gabbro, we employ equation (4b) and the previously measured spall strength of Lange et al. [1984] of $147 \pm 9 \mathrm{MPa}$ for a tensile stress duration of $1.07 \mu \mathrm{s}$ to obtain a fracture toughness of 5.23 $\mathrm{MPa} \mathrm{m}^{1 / 2}$. (The latter is an upper limit as here $\mathrm{K}_{\mathrm{IC}}$ is the stress intensity for the onset of crack growth.) Substituting into (A1) yields impact stresses of 18 and $118 \mathrm{GPa}$ for the limestone and gabbro experiments. One-dimensional impedance match solutions using calcite [Kalashnikov et al., 1973] and the Centerville diabase [McQueen et al., 1967] equations of state with lead and steel yield impact pressures of 11 and $88 \mathrm{GPa}$. Considering the approximations made, the agreement is good and we conclude that (A1) yields a good approximation to the linear extent of shock damage.

Acknowledgments. Research supported by AFOSR and NASA. Contribution 4996, Division of Geological and Planetary Sciences. We appreciate receiving helpful suggestions for improving the paper from one of the reviewers.

\section{REFERENCES}

Ackerman, H. D., R. H. Godson, and J. S. Wathins, A seismic refraction technique used for subsurface investigations at Meteor Crater, Arizona, J. Geophys. Res., 80, 765-775, 1975.

Ackerman, H. D., J. A. Grow, and J. M. Williams, Seismic refraction survey of OAK Crater, U.S. Geol. Surv. Bull., 1678, E1-E18, 1986.

Ahrens, T. J., Application of shock wave data to earth and planetary science, in Shock Waves in Condensed Matter, edited by Y. M. Gupta, pp. 571-588, Plenum, New York, 1986.

Ahrens, T. J., and V. G. Gregson, Jr., Shock compression of crustal rocks: Data for quartz, calcite and plagioclase rocks, J. Geophys. Res., 69, 4839-4874, 1964.

Ahrens, T. J., and J. D. O'Keefe, Equation of state and impact-induced shock-wave attenuation on the Moon, in Impact and Explosion Cratering, edited by D. J. Roddy et al., pp. 639-656, Pergamon, New York, 1977.

Anderson, D. L., B. Minster, and D. Cole, The effect of oriented cracks on seismic velocities, J. Geophys. Res., 79, 4011-4015, 1974.

Anstis, G. R., P. Chantikul, B. R. Lawn, and D. B. Marshall, A critical evaluation of indentation techniques for measuring fracture toughness, I, Direct crack measurements, J. Am. Ceram. Soc., 64, 533-538, 1981.

Ashby, M. F., and C. G. Sammis, The damage mechanics of brittle solids in compression, Pure Appl. Geophys., 133, 489-521, 1990.

Christensen, N. I., Seismic velocities, in Handbook of Physical Properties of Rock, vol. 2, edited by R. S. Carmichael, pp. 1-228, CRC Press, Boca Raton, Fla., 1982.

Cohn, S. N., and T. J. Ahrens, Dynamic tensile strength of lunar rock types, $J$. Geophys. Res., 86, 1794-1802, 1981.

Dvorak, J., and R. J. Phillips, The nature of the gravity anomalies associated with large young lunar craters, Geophys. Res. Lett., 4, 380-382, 1977.

Field, J. E., Brittle fracture: Its study and application, Contemp. Phys., 12, 1-31, 1971.

Grady, D. E., Shock deformation of brittle solids, $J$. Geophys. Res., 85, 913-924, 1980.

Grady, D. E., and M. E. Kipp, The micromechanics of impact fracture of rock, Int. J. Rock Mech. Min. Sci., 16, 293302, 1979.

Grady, D. E., and M. E. Kipp, Dynamic rock fragmentation, in Fracture Mechanics of Rock, edited by B. K. Atkinson, Pp. 429-475, Academic, San Diego, Calif., 1987.

Hadley, K., Comparison of calculated and observed crack densities and seismic velocities in Westerly granite, $J$. Geophys. Res., 81, 3484-3494, 1976.

Hajnal, Z., D. Scott, and P. B. Robertson, Reflection study of the Haughton impact structure, J. Geophys. Res., 93, 11,930-11,942, 1988.

Horaii, H., and S. Nemat-Nasser, Brittle failure in compression: Splitting, faulting, and brittle-ductile transition, Philos. Trans. R. Soc. London, 319, 337-374, 1986.

Hörz, F., Structural and mineralogical evaluation of an experimentally produced impact crater in granite, Contrib. Mineral. Petrol., 21, 365-377, 1969.

Ingraffea, A. R., Theory of crack initiation and propagation in rock, in Fracture Mechanics of Rock, edited by B. K. Atkinson, pp. 71-110, Academic, San Diego, Calif., 1987.

Ingraffea, A. R., K. L. Gunsallus, J. F. Beech, and P. P. Nelson, A short-rod based system for fracture toughness testing of rock, in Chevron-Notched Specimens: Testing and Stress Analysis, ASTM Spec. Tech. Publ., STP 855, 152-166, 1984.

Ingraffea, A. R., and R. A. Schmidt, Experimental verification of a fracture mechanics model for tensile strength prediction of Indiana limestone, Proc. U.S. Symp. Rock Mech., 19th, 247-253, 1978.

Isida, M., and S. Nemat-Nasser, On the mechanics of crack growth and its effects on the overall response of brittle porous solids, Acta Metall., 35, 2887-2898, 1987.

Ivanov, B. A., Z-model with shear bulking and gravity anomalies above impact craters, (abstract), Lunar Planet. Sci., XX, 446-447, 1989.

Kalashnikov, N. G., M. N. Pavlovskiy, G. V. Simakov, and R. F. Trunin, Dynamic compressibility of calcite-group minerals, Izv. Acad. Sci. USSR Phys. Solid Earth, 2, 2329, 1973.

Lange, M. A., T. J. Ahrens, and M. B. Boslough, Impact cratering and spall fracture of gabbro, Icarus, 58, 383395, 1984.

Maurer, W. C., and J. S. Rinehart, Impact crater formation in rock, J. Appl. Phys., 31, 1247-1252, 1960.

McQueen, R. J., S. P. Marsh, and J. N. Fritz, Hugoniot equation of state of twelve rocks, J. Geophys. Res., 72, 4999-5036, 1967. 
Melosh, H. J., Impact ejection, spallation, and the origin of meteorites, Icarus, 59, 234-260, 1984.

Melosh, H. J., Impact Cratering, A Geologic Process, pp. 1245, Oxford University Press, New York, 1989.

Moore, H. J., D. E. Gault, and R. V. Lugn, Experimental impact craters in basalt, Trans. Soc. Min. Eng., 226, 258-262, 1963.

Nur, A., and G. Simmons, The effect of saturation on velocity in low porosity rock, Earth Planet. Sci. Lett., 7, 183-193, 1969.

O'Connell, R. J., and B. Budiansky, Seismic velocities in dry and saturated cracked solids, J. Geophys. Res., 79, 5412-5426, 1974.

O'Keefe, J. D., and T. J. Ahrens, Planetary impacts: The effects of gravity, size, and velocity on the scaling of crater geometry and the transition from single to complex craters, (abstraci), Lunar Planet. Sci. Conf., XX, 810-811, 1989.

Pohl, J., D. Stoffler, H. Gall, and K. Emstson, The Ries impact crater, in Impact and Explosion Cratering, edited by D. J. Roddy, et al., pp. 343-404, Pergamon, New York, 1977.

Polanskey, C., and T. J. Ahrens, Impact spallation experiments: Fracture patterns and spall velocities, Icarus, 87, 140-155, 1990.

Rinehart, J. S., Dynamic fracture strength of rocks, Proc. Symp. Rock Mech., 7th, 1, 205-208, 1965.

Rubin, A. M., and T. J. Ahrens, Dynamic tensile failure induced velocity deficits in rock, Geophys. Res. Lett., 18, 219-223, 1991.

Sammis, C. G., and M. F. Ashby, The failure of brittle porous solids under compressive stress states, Acta Metall., 34, 511-526, 1986.

Schmidt, R. A., Fracture-toughnèss testing of limestone, Exp. Mech., 16, 161-167, 1976.

Selberg, H. L., Transient compression waves from spherical and cylindrical cavities, Ark. Fys., 5, 97-108, 1952.

Shibuya, T., and I. Nakahara, The semi-infinite body subjected to a concentrated impact load on the surface, Bull. Jpn. Soc. Mech. Eng., I 1, 983-992, 1968.

Shockey, D. A., D. R. Curran, L. Seaman, J. T. Rosenberg, and C. F. Peterson, Fragmentation of rock under dynamic loads, Int. J. Rock Mech. Min. Sci., 11, 303-317, 1974.

Short, N. M., Nuclear-explosion-induced microdeformation of rocks: An aid to the recognition of meteorite impact structures, in Shock Metamorphism of Natural Materials, edited by B. M. French and N. M. Short, Pp. 185-210, Mono, Baltimore, Md., 1968.

Simmons, G., T. Todd, and H. Wang, The $25-\mathrm{km}$ discontinuity: Implications for lunar history, Science, 182, 158-161, 1973.

Swain, M. V., and J. T. Hagen, Rayleigh wave interaction with, and the extension of, microcracks, J. Mater. Sci., $15,387-404,1980$.

Toksöz, M. N., C. H. Cheng, and A. Timur, Velocities of seismic waves in porous rocks, Geophysics, 41, 621-645, 1976.

Walsh, J. B., The effect of cracks on the uniaxial elastic compression of rocks, J. Geophys. Res., 70, 399-411, 1965.

Wong, T.-F., and R. Biegel, Effects of pressure on the micromechanics of faulting in San Marcos gabbro, $J$. Struc. Geol., 7, 737-749, 1985.

Zimmerman, R. W., and M. S. King, Propagation of acoustic waves through cracks rock, in Rock Masses, edited by $\mathrm{E}$. Ashworth, pp. 739-745, A. A. Balkema, Boston, Mass., 1985.

T. J. Ahrens, Seismological Laboratory 252-21, California Institute of Technology, Pasadena, CA 91125.

A. M. Rubin, Department of Geological Sciences, Princeton University, Princeton, NJ 08544

(Received January 24, 1992; revised October 29, 1992;

accepted November 11, 1992.) 